\title{
Making the Case for Democracy
}

\author{
Anonymized
}

Anonymized

June 29, 2022

\begin{abstract}
Ordinary citizens are considered bulwarks against democratic backsliding. Yet, citizens' commitment to democracy below the surface is sometimes fragile and crises can induce anxieties and discontent. We propose "democratic persuasion" as a theorydriven, actionable intervention to foster the resilience of citizens' commitment to liberal democracy. "Democratic persuasion" requires that political elites actively make the case for democracy and discuss democracy's inherent trade-offs while engaging existing doubts and misperceptions. During the Covid-19 pandemic, which brought these trade-offs to the fore, we invited citizens on facebook to attend one of sixteen Zoom town halls to discuss pandemic politics with a German member of parliament. Each MP conducted two town halls and we randomly assigned, when they employed "democratic persuasion". The field-experiment demonstrates substantial effects on some, but not all, indicators of democratic commitment, showcasing the academic and practical value of this emerging line of research on strengthening societal foundations of liberal democracies.
\end{abstract}

Keywords: democratic backsliding; field-experiment; randomized control trial; support for democracy 


\section{Introduction}

Liberal democracy is under pressure. In the midst of a global democratic recession (Lührmann and Lindberg 2019), scholars and activists are increasingly aware that the persistence of democracy cannot be taken for granted - even in countries where democracy appeared to have taken root. Unlike in previous phases of autocratization, democracy today declines gradually and under legal disguise (Lührmann and Lindberg 2019; Runciman 2018). Orbán, Bolsonaro, Trump, and other contemporary leaders with authoritarian tendencies came into office through regular democratic elections and have enjoyed significant support among citizens. Hence, nowadays, democratic backsliding in industrialized countries is associated less with military coups than with ordinary citizens in the voting booth (Bermeo 2016).

As democracy researchers have long considered vigilant citizens as a safeguard against authoritarian takeover (Linz and Stepan 1996), the commitment of ordinary citizens to democracy is crucial. While most citizens in democratic societies strongly support abstract notions of popular rule (Wuttke, Gavras, and Schoen 2020), below the surface, democracy's societal pillars appear fragile. There is widespread discontent with democracy's working (Foa et al. 2020) and many citizens do not endorse key principles of liberal democracy such as pluralism and the balance of legitimate competing interests in a polity (Kirsch and Welzel 2018). And even when citizens do support liberal-democratic values, many do not elevate these principles over partisan preferences (Foa et al. 2020; Graham and Svolik 2020).

The current political climate offers plenty of opportunities for political entrepreneurs (De Vries and Hobolt 2020) to exploit the fragility of citizens' commitment to liberal democracy (Arceneaux et al. 2020; Nachtwey and Frei 2021). The Covid-19 crisis has fostered and exacerbated already existing anxieties, discontent, and uncertainties (Becher et al. 2021; Bor, Jørgensen, and Petersen 2021; Daniele et al. 2020), all of which can make citizens more open to authoritarian temptations (Stenner 2005). Digital media (Jungherr, Rivero, and Gayo-Avello 2020) allow these political entrepreneurs to channel and ratchet up doubts and anxieties that invariably arise in times of existential crisis. 
Indeed, in the United States, France, Germany, and other Western democracies, debates surrounding the Covid-19 response turned into discussions about democracy itself. Anti-system forces attempted to seize on concerns regarding executive-overreach and restrictions on civil liberties and direct those into opposition against the liberal-democratic order as a whole (Amat et al. 2020; Kolvani et al. 2021). As scholarship has accumulated knowledge about the structural weaknesses of and momentary threats to citizen commitment to democracy, this study takes a turn towards practical interventions that can be applied by those political elites who are committed to maintaining liberal democracy.

We ask: "what can be done to bolster the resilience of citizen commitment to liberal democracy in times of crisis"?

Redefining the concept of "democratic persuasion" (Brettschneider 2010), this study explores the efficacy of a theory-driven intervention to foster citizen commitment to liberal democracy. We test if political elites have the power to increase citizen support for the democratic system of government if they use their communicative resources to engage concrete concerns of ordinary citizens and actively make the case for the liberal variant of democracy. Specifically, in 16 digital town hall meetings between ordinary citizens and members of German parliaments, we randomly assigned if the legislators spent some of their time on the deliberate attempt to persuade the attending citizens of the value of liberal democracy. Results show that democratic persuasion can have sizable effects on some, but not all, indicators of citizen commitment to liberal democracy, at least in the short term.

\section{Citizen commitment to democracy in times of crisis}

Empirical democracy research does not provide us with commonly agreed-upon criteria of what it means for a citizen to be committed to democracy. Yet, classics in the field of democracy research as well as more recent contributions help us identify specific factors that could increase the likelihood that citizens stand up for democracy when it really matters. 
As contemporary democratic backsliding often occurs in the name of democracy itself (Runciman 2018), effective democratic commitment requires awareness and endorsement of the principles that underpin democracy so their violations do not go unnoticed. The principles that underpin liberal democracy — pluralism, compromise, rule of law (Skaaning 2021) - are particularly relevant here, as the liberal variant of democracy, at least in principle, realizes both liberty and equality, and is the specific target of current attacks (Pappas 2019).

In addition to support for pluralist values, another cornerstone of commitment to democracy is the perception of the democratic system as legitimate (Diamond 2020). Even among convinced liberal democrats, perceptions of legitimacy cannot be taken as a given because perceived legitimacy erodes when citizens feel -correctly or not- that the system of government as it actually exists no longer lives up to its ideals (Lipset 1981). Legitimacy perceptions also depend on evaluations of the political system as it currently works. While satisfaction with democracy is a chronically ambiguous concept (Valgarðsson and Devine 2021), it can be considered one of the facets of democratic commitment because democratic discontent undermines citizens' willingness to stand up for the democratic system they live in when under threat (Saikkonen and Christensen 2021).

Having laid out some of its facets, what is the current state of citizens' commitment to democracy? Contrary to some narratives, recent evidence suggests no fundamental erosion of citizen support for the democratic idea as the abstract notion of democracy remains popular (Wuttke, Gavras, and Schoen 2020). Yet, the state of affairs seems more fragile when we consider commitment to the liberal variant of democracy in the multi-faceted way described above. Some citizens subscribe to alternative conceptions of democracy, for instance to the majoritarian or authoritarian variant (Wunsch, Jacob, and Derksen 2022). Moreover, large swaths of citizens are dissatisfied with democracy's working (Foa et al. 2020). Many citizens lack an understanding of the principles that underlie the liberal-democratic order (Kirsch and Welzel 2018) and less than one in ten citizens elevate democracy over party and stands up for democratic principles when it 
really matters (Graham and Svolik 2020). Hence, despite generally favorable attitudes in the abstract, the commitment of many ordinary citizens exhibits weaknesses that aspiring autocrats can exploit in an attempt to subvert democratic norms and practices (Bermeo 2020).

The existential crisis caused by the Covid-19 pandemic is a case in point, which highlights the vulnerabilities of democratic systems. The pandemic has revealed how easily existing vulnerabilities in combination with external shocks create windows of opportunity for entrepreneurial forces at the extremes to turn parts of the population against the system. Existential crises incite anxiety and uncertainty. While some citizens develop even stronger allegiance to the political system under these circumstances (see, eg., rally-around-the flag effects, (Schraff 2020)), for others, doubts and discontent increase (Bor, Jørgensen, and Petersen 2021). The complexities of rapidly changing circumstances fuel doubts. The necessarily imperfect outputs of democratic decision-making in unprecedented times fuel discontent. In the specific case of the Covid-19 pandemic, another source of anxiety was the decision of democratic (and undemocratic) governments to mitigate health risks through temporary but wide-ranging restrictions of individual liberties. Even when enacted through democratic processes, these decisions may have led some citizens with democratic convictions to question the legitimacy not only of particular policies, but of the system itself (Amat et al. 2020).

In the United States, France, Germany, and other liberal democracies, extremist, populist and fringe groups were quick to seize on these sentiments. In Germany, for instance, 'Querdenken' brought thousands to the streets in protest against the 'Corona dictatorship' and the radical-right Alternative für Deutschland (AfD) claimed that Germany was 'no longer a democratic country' (Küppers and Reiser 2021; Nachtwey, Schäfer, and Frei 2020). Similar protests took place in France and the Netherlands (see Guardian France 24. France 24). In other words, the opponents of liberal democracy do not forfeit the chance of capitalizing on structural or crisis-induced weaknesses of citizens' commitment to democracy. This realization raises the question of potential counter-strategies that proponents of liberal democracy can employ when this system of government is under 
pressure.

A starting point for devising such a strategy is to notice that anti-system movements often avoid overt anti-democratic or anti-liberal stances (Küppers and Reiser 2021; Nachtwey, Schäfer, and Frei 2020; Nachtwey and Frei 2021). To the contrary, many adopt pro-democratic or pro-liberal rhetoric which allows them to address the significant share of citizens who support the liberal-democratic idea, but reject its practice. Another point worth noting is that some of the concerns have some foundation in reality, such as highlighting and questioning the severe infringement of individual liberties during the pandemic. While generally legitimate, this line of criticism may breed destabilizing potential when combined with a denial of trade-offs and value conflicts. In pluralist societies, the need to balance competing goals and interests is inherent to political decision-making. Democracy's legitimacy may erode when necessarily imperfect policy outcomes are not recognized as intractable problems that require compromise and balance but portrayed as systemic failures of an outright corrupt elite (Müller 2021). While most frequently debated with respect to anonymous digital public spheres (Guess et al. 2020; Jungherr, Rivero, and Gayo-Avello 2020), throughout the pandemic, dynamics of over-generalisation and the misconstruction of facts occurred offline and online across many liberal democracies.

Hence, the key challenge is to engage with concerns that are sometimes stirred or exploited by ill-intended political entrepreneurs (De Vries and Hobolt 2020), but which may nevertheless express concerns that contain a kernel of truth or that spring from pro-democratic motivations. The provision of context is therefore crucial. While low levels of satisfaction with democracy, in some contexts, where backsliding is present, reflect reality, in other contexts, such as in Germany during the Covid-19 pandemic, low levels of satisfaction with democracy can open the gates for forces that attempt to to transform the system of government into a more authoritarian type of democracy. We argue that it is crucial to not leave citizens' concerns unaddressed, but to offer context and alternative frames of interpretation. By engaging with citizens' arguments, they might be willing to consider system-supporting frames instead of entrenching concerns in 
system-destabilizing mindsets.

\section{Making the Case for Democracy}

We know that elites can influence public opinion (Lenz 2012; Zaller 1992). Yet, political elites in particular parties are usually incentivized to put their communicative power in the service of instrumental goals such as winning office or building support for their party (Cantoni and Pons 2021; Wantchekon 2017). We ask what would happen if politicians spent a share of their discursive capital not on their own candidacies, other parties or policies (López-Moctezuma et al. 2020; Wantchekon 2017), but on explaining the value of the democratic system that allows election debates and policy discussions to happen

in the first place: Can political elites utilize their public platform to strengthen citizen commitment to democracy, and if yes, how can this be achieved? In a time where democracy itself is at stake, pro-democracy politicians should have an interest in working to sustain the liberal democratic system of government.

Interventions to foster democratic attitudes have so far concentrated on societies in transition to democracy (Finkel, Neundorf, and Rascon Ramirez 2021; Gibson 1998) or on fragile states (Mvukiyehe and Samii 2017). As the fragility of established democracies becomes increasingly apparent, there is a clear need to trial democracy-supporting interventions within established democracies. Most of these interventions rightly focus on what political elites can do to counter explicitly anti-democratic behavior and rhetoric of fellow politicians (Hobolt and Osnabrügge 2022). Our focus, however, is on what politicians can do to strengthen the resilience of liberal democracy at the societal level by addressing citizens' concerns.

One line of research that is relevant to understanding the effects of democracy-related communication examines counter-strategies to fake news, misinformation and belief correction (Nyhan 2020). These studies assume the existence of factually correct and incorrect assertions and seek to correct inaccurate believes by communicating what is true and false. While this research highlights the need for persuasive interventions on democracy, 
impersonal fact spreading intervention were not always successful and have, under certain conditions, even backfired (Nyhan 2020).

Legislator-to-citizen communication in the tradition of deliberative theory may help overcome some of the weaknesses of misperception-correcting interventions. We know that personal encounters between politicians and citizens can be an effective way of shaping citizens' attitudes (Cantoni and Pons 2021; Foos 2018; Wantchekon 2017). In terms of format, town halls have been used as popular fora where politicians can directly communicate with a relatively large number of citizens (Abernathy et al. 2019; Wantchekon 2017; López-Moctezuma et al. 2020; Minozzi et al. 2015). In terms of communication style, we know that individuals are more likely to rethink attitudes if conversations are conducted in a respectful manner (Muradova 2021). Survey-experimental evidence shows higher efficacy of political persuasion when it respectfully acknowledges the recipient's point of view (Xu and Petty 2021) and evidence from the field supports the value of non-judgmental approaches to attitude change (Kalla and Broockman 2020). Altogether, these findings point to direct encounters between politicians and citizens in a non-judgmental, respectful atmosphere as a promising strategy for fostering commitment to democracy.

Such an approach would move beyond various forms of civic education as the bestknown form of pro-democracy interventions (Finkel et al. 2022). While civic education often addresses the younger generation, democratic persuasion concerns mostly adults. Adult citizens are no blank slates but come with years or decades of experience with democratic politics which may have given rise to the ambivalence towards democracy expressed in surveys. As political persuasion is more successful when it engages with the beliefs that citizens' hold in the first place (Altay et al. 2022), democratic persuasion may be most effective when it engages with citizens' existing concerns directed at the democratic process, representatives, and outcomes. 


\section{Democratic persuasion}

To specify how exactly encounters between citizens and politicians may foster the resilience of citizen commitment to democracy, we employ and redefine the concept of democratic persuasion (Brettschneider 2010) as the deliberate attempt to persuade the public in favor of democratic decision-making by acknowledging legitimate criticism, while actively making the case for democracy.

Democratic persuasion builds on the diagnosis of wide-spread support for democracy in the abstract that often comes with specific concerns about its practice and low awareness of democracy's underlying principles and procedures. Its primary audience is thus not the small fraction of militant opponents to democracy but democratic persuasion engages concerns of wavering democrats who either do not fully embrace liberal-democratic principles or who have grown disenchanted with current democratic practice (see V-DEM $(2020))$.

Acknowledging a reality where some citizens have doubts on the workings of democracy, democratic persuasion has two components. Each offers alternative frames of interpretation to citizens with fragile commitments to democracy. First, it aims at explaining the intrinsic value of democratic decision-making as well as its inherent trade-offs and inevitable imperfections. Second, it engages doubts about democracy and uses the honest exchange of opinions as an opportunity to challenge misperceptions and false information.

We expect that democratic persuasion will foster citizen commitment to liberal democracy (see appendix 9.11 for results on a second pre-registered hypothesis):

Democratic persuasion hypothesis Exposure to democratic persuasion ${ }^{1}{ }^{1}$ increases support for democracy and facilitates understanding of the trade-offs inherent in political decision-making, increases trust in politicians and reduces reservations towards the political process and democratic institutions.

\footnotetext{
${ }^{1}$ We referred to the treatment as "democratic talk" in the PAP.
} 


\section{Design}

\subsection{Set-up}

We organized 16 digital town hall meetings between ordinary citizens and members of German state and federal parliaments, ostensibly on the topic of the Covid-19 pandemic. We worked together with politicians and randomly assigned half of the town halls to include the democratic persuasion intervention, where politicians made the case for democracy, following a short lightning talk about democracy in times of Covid-19.2 We implemented this field experiment in collaboration with eight federal and state legislators, representing 5 German parties. 4 legislators were members of governing parties at the federal level (1 CDU, $3 \mathrm{SPD}$ ) and 4 legislators were members of federal opposition parties (2 Free Democrats (FDP), 1 Green, 1 Left Party). There was no representative of the radical right AfD present. This decision was taken because we expected that politicians affiliated with the AfD would be unlikely to subscribe to the intervention. Moreover, given that many politicians affiliated with the AfD opposed the Covid-19 vaccine, there was a small chance that misinformation spread in the town halls could have led to physical harm among participants. We hence opted to err on the side of caution. The town halls took place between November 2020 and January 2021, in the midst of the 'second wave' of the Covid-19 pandemic in Germany. Before the town hall, we pre-registered the theoretical arguments, hypotheses, power analysis and the analysis syntax (see Appendix 9.12 for the link to the de-identified version of the PAP).

\subsection{Sample}

Social media serves as a platform to spread misinformation and extremist rhetoric relating to both the Covid-19 pandemic (Küppers and Reiser 2021) and democratic practices (Guess, Nyhan, and Reifler 2020). We therefore deliberately used facebook ads to recruit a heterogeneous sample of German citizens via quota sampling to participate in one of the 16 Zoom town halls. The town halls were advertised on facebook as opportunities

\footnotetext{
${ }^{2}$ The study was reviewed and approved by the Research Ethics Committee at Anonymized University under Ref: 11146.
} 
for citizens to meet members of parliament and discuss with them about Covid-19 without explicit reference to democracy. Interested facebook users were directed to an online survey where they were informed about the town halls and the associated academic study, gave consent on participation and data processing and filled in a baseline survey. During the survey, six respondents were screened out for meeting the criteria of militant anti-democracy (see Appendix 9.1). All other respondents were asked to select one town hall meeting from a list of town halls with information on the date, the name of the participating politician, and the location of the politician's electoral district, but blind to the experimental condition, to which the town hall was assigned. We also did not indicate the party affiliation of the politician but since the name of the politician was displayed participants' party preferences played a (small) role in their town hall choice (see Appendix 9.1). Yet, because pair randomization was conducted within politicians, there is no reason to expect systematic differences in potential outcomes between town halls conducted by the same legislator. We show balance tests in Appendix 9.9. Overall, treatment and control groups are well balanced on pre-treatment attitudes and most demographics. Given the multiple tests we conduct, there is some demographic covariate imbalance on age groups and whether respondents are based in East Germany (more respondents in the treatment group are based in East Germany). We report both unadjusted and covariate-adjusted CACE estimates throughout the paper.

\subsection{Experimental conditions}

Each representative conducted two town halls that each lasted 60 minutes. We used pair (block) random assignment to assign one of the two town halls to the democratic persuasion condition. Before the town hall took place, we met each politician and their staff to explain the set-up and the two experimental conditions. We suggested that legislators go about the standard town hall as they usually would and that in the treatment condition they spend significant time on democratic persuasion as defined above. We explained the strategy in detail to the participating politicians beforehand and all politicians were willing to implement the intervention as described. Since the condition was 
randomly assigned, some politicians first conducted the standard town hall, followed by the democratic persuasion town hall, while others were assigned to do the reverse. Subjects attending the town halls knew that the event was evaluated as part of an academic study but were unaware of the specific experimental condition they found themselves in. The experiment was approved by the ethics review committee of Anonymized University. We discuss the ethics of the experiment and of the democratic persuasion intervention in detail in Appendix 9.7 .

Each town hall proceeded according to the following script: The moderator opened the town hall and welcomed subjects, introducing the member of parliament and explaining the proceedings and how participants could ask questions. After the introduction, the interventions diverged. Following Broockman and Kalla (2016), the democratic persuasion intervention consisted of a bundle of elements, with a view of manipulating individual elements of the intervention in subsequent work after having first tested the efficacy of the broader concept (Kalla and Broockman 2020). Central to the intervention was that politicians were instructed to connect their discussion of pandemic politics with the recurring attempt to engage in democratic persuasion. That is, politicians were encouraged to circle back to the question of democracy where possible during the ensuing Q\&A, proactively addressing concerns about the practice of democracy and explaining the process of democratic decision-making in a pluralistic society.

This element of our intervention was embedded in bundle of other manifestations of democratic persuasion. After the introduction, subjects in the treatment condition listened to a short presentation, lasting around 4-5 minutes, about "Democracy in times of Covid-19" by a political scientist who we consider as representing societal elites with communicative power. The presentation challenged the thesis that "during the pandemic, civil liberties were restricted to an extent that it is no longer possible to speak of proper democracy in this country". The presentation implemented democratic persuasion by highlighting the trade-offs democratic decision-making faced between individual freedoms such as the freedom of assembly and the state's duty to avoid harm (see Online Repository). After the presentation, the MP took up the baton and engaged in demo- 
cratic persuasion during short introductory remarks that lasted around 5 minutes. In the standard town hall, the politician was invited to speak for 10 minutes about relevant aspects of the Covid-19 pandemic such as economic and public health measures, but did not stray into discussions on democracy, unless explicitly asked by one of the attendants in the Q\&A. There was no presentation element to the standard town hall condition. A research assistant (confederate) participated in all town halls who served as an icebreaker to ask one of the first questions. In the democratic persuasion town halls the confederate's question concerned the short-comings of democracy during the pandemic. In the standard town halls, the question concerned practicalities of government policies.

In both experimental conditions, after the MP's remarks the moderator opened the Q\&A and citizens could ask questions in the order in which they raised their virtual hands on Zoom. The moderator aimed to ensure that all participants who wanted to ask a question were able to do so. The size of the town halls varied and ranged from 8 to 30 participants (5 to 19 wave 2 respondents), with a mean of 17 participants (13 wave 2 respondents).

\subsection{Measures}

Attitudinal outcomes were measured via a three-wave panel survey. Subjects completed the baseline survey after sign-up via facebook. The first post-treatment survey was administered at the end of the town hall via Zoom poll. A second post-treatment wave was distributed one month after the town hall, but the analysis of this was not pre-registered. 183 subjects answered the first post-treatment wave on Zoom, and 144 participants answered the second post-treatment wave.

We pre-registered four primary outcomes which are detailed in the results section (see appendix 9.3 for question wordings): satisfaction with democracy (measured on a scale from 1-5), support for pluralism (scale ranging from 1-4), concern about democratic rights (binary, 0/1) and a 3-point behavioral action scale which included whether subjects signed two petitions to defend democratic pluralism and signed-up for a "democracy newsletter". We also measured agreement with trust in politicians, with the Churchill sentiment on 
democracy, and with populist attitudes, but due to strong floor and ceiling effects pretreatment, we pre-registered classifying those measures as secondary and report results in the appendix (see Appendix 9.10). We also measured support for Covid-19 social distancing measures as a secondary outcome.

\subsection{Analysis}

We estimate treatment effects based on randomization inference using one-tailed tests (as pre-registered), testing whether we can reject the sharp null hypothesis of no positive effect for any subject. The randomization-inference procedure accounts for pair-random assignment of town halls to treatment and control within each politician and the fact that subjects are clustered within town halls. The comparison is hence between subjects who attended the treatment town hall and subjects who attended the control town hall, held by the same politician. Since subjects were not aware of which experimental condition the town hall they attended was assigned to, attendance at the town hall is not a function of treatment assignment. The quantity we are interested in therefore corresponds to the Complier Average Causal Effect. We report the unadjusted and covariate-adjusted difference-in-means estimates (covariates: pre-treatment measure of the outcome, gender, age, education, ideology, region, party ID, all measured pre-treatment).

\section{Results}

Our town halls took place amid contentious and consequential times. For many participants, the issues at stake were pressing and personal. And for many, it was the first time they had the opportunity to discuss their views on the Covid-19 crisis in a public forum or with a member of parliament. Table 1 shows that citizens went into these gatherings with diverging viewpoints. The town halls attracted a diversity of opinions, reflecting the heated discussions that took place in Germany and many other countries in the winter of $2020 / 2021$.

Both left- and right-learning citizens joined the town hall meetings, yielding a com- 
Table 1: Relevant variables before treatment

\begin{tabular}{|c|c|c|c|c|c|}
\hline & Min & Max & Mean & Boxplot & Histogram \\
\hline Left-right ideology & 1.00 & 10.00 & 4.47 & レー & तПగ్- \\
\hline Democracy: best form to govern & 1 & 5 & 4.65 & $\cdots \vdash 1$ & لهـ \\
\hline Democracy: weak decisions (r) & 1 & 5 & 4.07 & •1 & ـ \\
\hline Satisfaction with democracy & 1 & 5 & 3.09 & $\vdash \vdash-1$ & 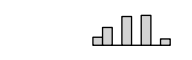 \\
\hline Pluralism & 1 & 4 & 3.34 & $\cdot \bullet-1$ & لمهـ \\
\hline Populist attitudes (r) & 0 & 12 & 5.61 & •ル・・ & ज्ञात \\
\hline Trust in Covid Politics & 1 & 5 & 2.47 & $11-1$ & 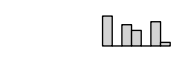 \\
\hline Gov is hiding info on Covid (r) & 1 & 5 & 3.33 & -1, & 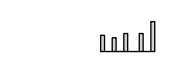 \\
\hline Concerned about democratic rights (r) & 1 & 5 & 2.64 & $10-1$ & 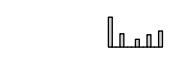 \\
\hline
\end{tabular}

Higher values indicate stronger commitment to democracy.

Populism, concerns about rights were measured on a binary scale in waves 2,3 .

position of ideological orientations among the participants that closely mirrors the distribution in the general population of German citizens (see Appendix 9.8). Attitudes are largely homogeneous and positive with respect to the abstract idea of democracy and the endorsement of pluralist principles, albeit there is meaningful variation in the latter measure. At the same time, among a share of participants, we also observe the expected fragility of citizen commitment to democracy. Against the backdrop of the Covid-19 crisis, a majority of participants expressed dissatisfaction with the democratic process. A sizable number also harbored concerns about the infringement of democratic rights during the pandemic. One in five participants accused the government of hiding important information on the pandemic. Hence, the sample of participants comprises a mix of committed and wavering democrats. How did exposure to democratic persuasion change their attitudes towards democracy?

Figure 1 provides a better idea of how the town halls unfolded in the two experimental conditions, based on the results of a keyness analysis of everything that was said in these meetings. Separately for politicians and participants, the plots show which terms were most distinct for the treatment (red) and control (blue) town halls.

The results confirm that politicians in the treatment condition carried out democratic persuasion as intended and spoke much more frequently about democracy. The analysis 
also reveals that, as politicians placed greater emphasis on democracy, the focus of the questions and comments by the participants changed in lockstep. Procedural and practical aspects of democracy moved into the foreground whereas medical and psychological implications of the pandemic were less important. 

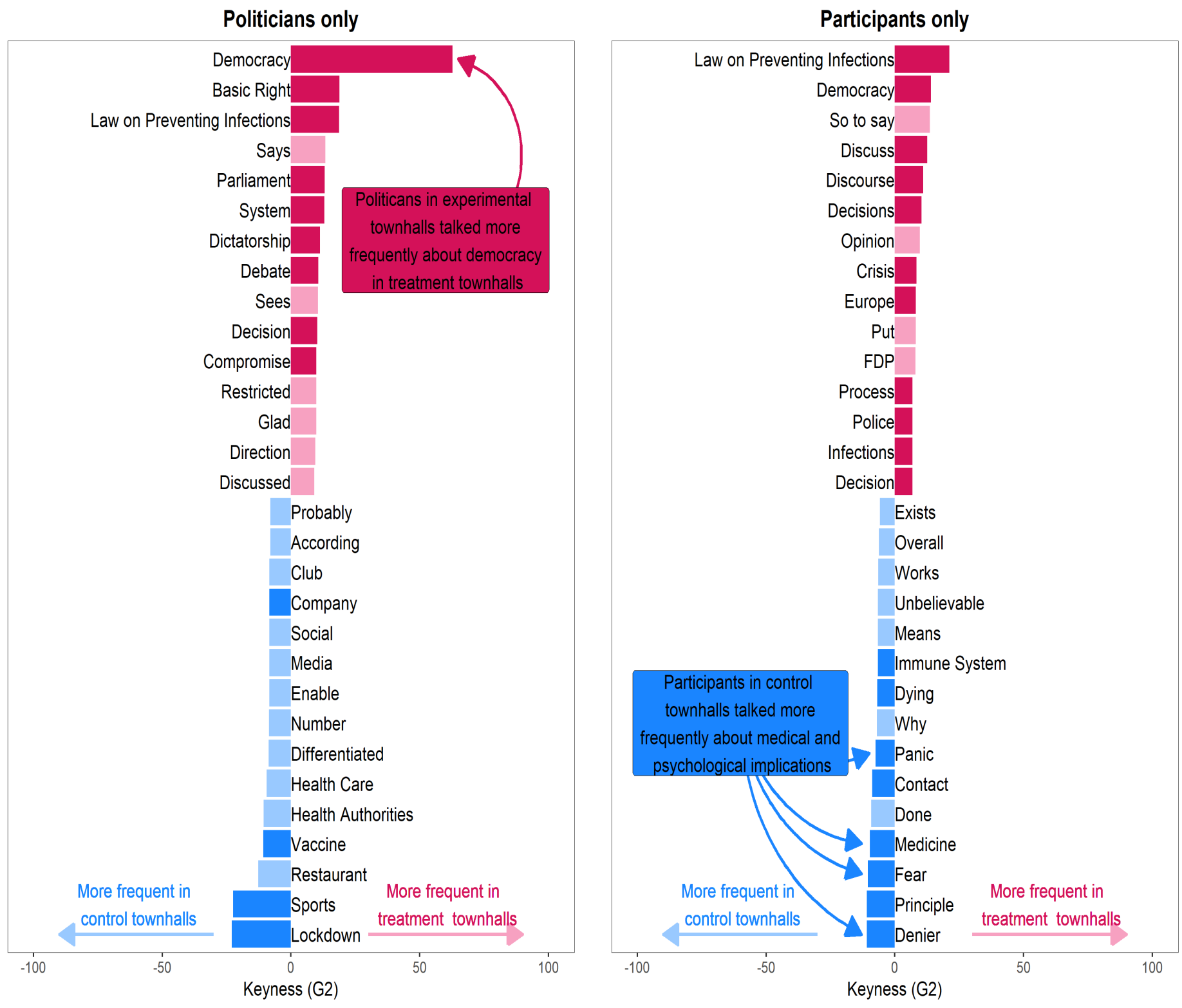

Figure 1: What was said in the democratic persuasion vs. control town hall 
Figure 1 also conveys a sense of how politicians tried to make the case for democracy. Politicians in the treatment condition emphasized fundamental principles of liberal democracy ("Basic rights"). They also discussed the procedures and institutions ("Law on Preventing Infections", "Parliament") through which democratic politics takes on the challenge of complex decision-making during the Covid-19 pandemic ("Debate", "Decisions", "Compromise").

Here is one example of how one politician of a governing party opened the discussion in the treatment condition. The quote showcases democratic persuasion's proactive engagement with existing concerns and the attempt to explain the principles and processes by which liberal-democratic politics responded to the crisis:

"I am looking forward to this dialogue in the time of the second lockdown (...) when many say our democracy has already been abolished and we live in a dictatorship. I disagree. What we have in terms of rule of law, executive, judiciary, legislative is outstanding. It could still be better. Government should no longer act by decree. We must uphold the prerogative of parliament's law also in times of a pandemic. This is one topic where we can learn from the mistakes we made early this year and we debate this in parliament on Wednesday. (...)

Any decision we take involves balancing the arguments of multiple sides. (...) No one was spoon-fed with wisdom. I hope, I and my party never believe to have a monopoly on the truth and I hope all citizens realize that (...) decisions are always compromises and that we can change our minds when receiving new information. (...) Democracy lives on disagreement. (...) We need to find ways to listen to each other and to then compromise. This is why I am now looking forward to an honest, civiliz discussion with you."

Participants recognized that politicians made the case for democracy in the treatment town halls. Figure 2 shows the results of a manipulation check: whether subjects correctly identified the theme of the town hall as "advocating for liberal democracy" among a set of four themes. The figure shows that subjects in the "democratic persuasion" condition were 26 percentage-points (24 percentage-points covariate-adjusted) more likely than subjects in the standard town hall condition to identify "liberal democracy advocacy" as the major theme of the democratic persuasion town hall. This difference is significant with $\mathrm{p}=0.001$ (one-sided), indicating that the manipulation succeeded.

Overall, the evidence presented so far shows that democracy took center stage in the 
treatment town halls. This has three implications. First, the results bolster confidence in the internal validity of the experiment. Second, as expected, politicians' usual way of communicating with citizens leaves ample room for the inclusion of democratic persuasion strategies. Finally, when encouraged to do so, the politicians in our town halls were willing and capable of employing democratic persuasion.

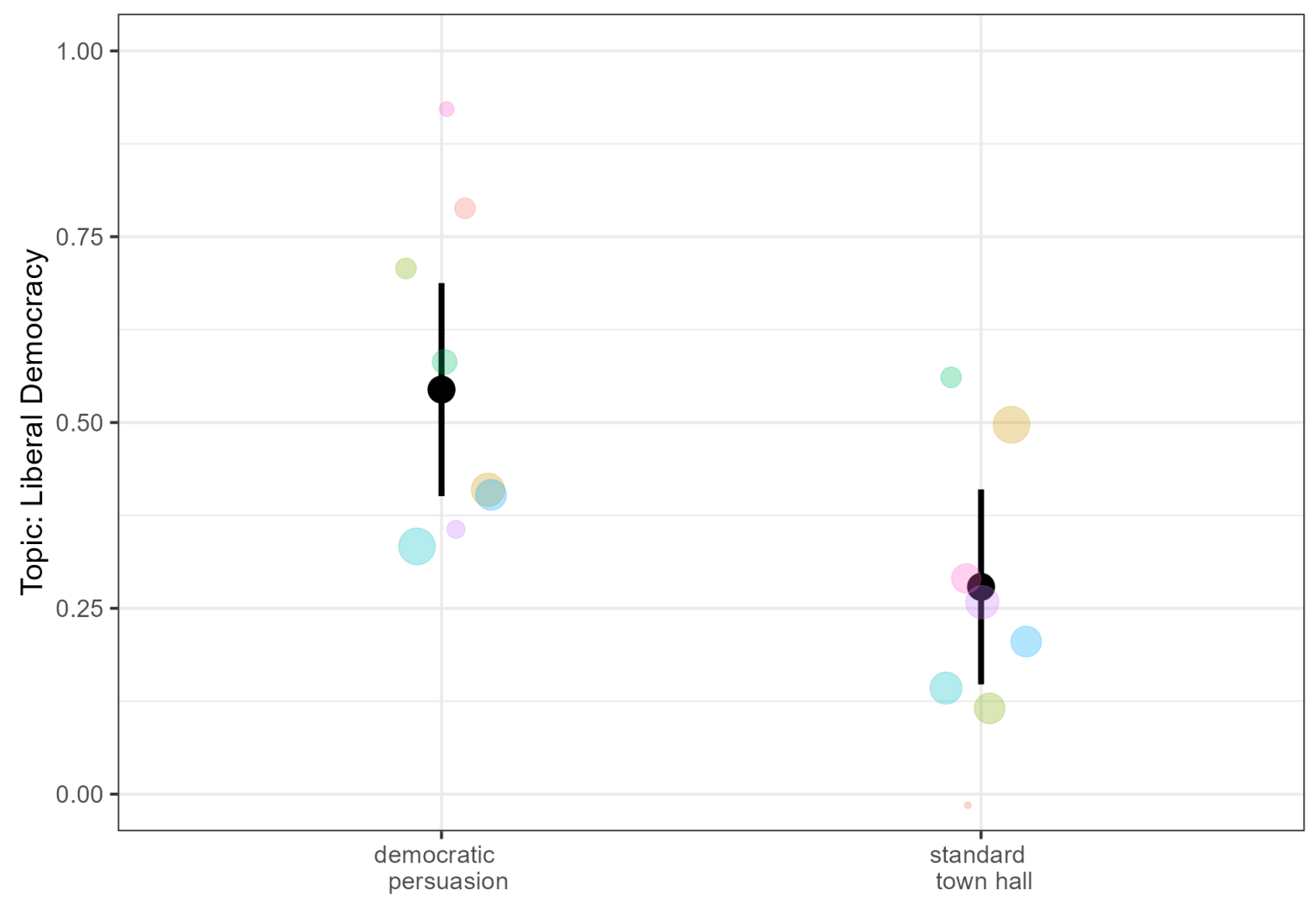

Figure 2: Manipulation Check

Moving to identifying the impact of democratic persuasion on citizen commitment to democracy, we observe some evidence that randomly assigned exposure to democratic persuasion made citizens more committed to democracy as they left the town hall meeting.

The left panel of Figure 3 reports mean levels of satisfaction with democracy, comparing participants who attended the democratic persuasion town hall to the participants in the standard town hall. Arguably, any interpretation of a population's satisfaction with democracy needs to be situated in its specific context. At the time of the town halls, entrepreneurs at the political fringes aggressively questioned the legitimacy of the government's pandemic response and stirred doubts whether Germany could still be considered 

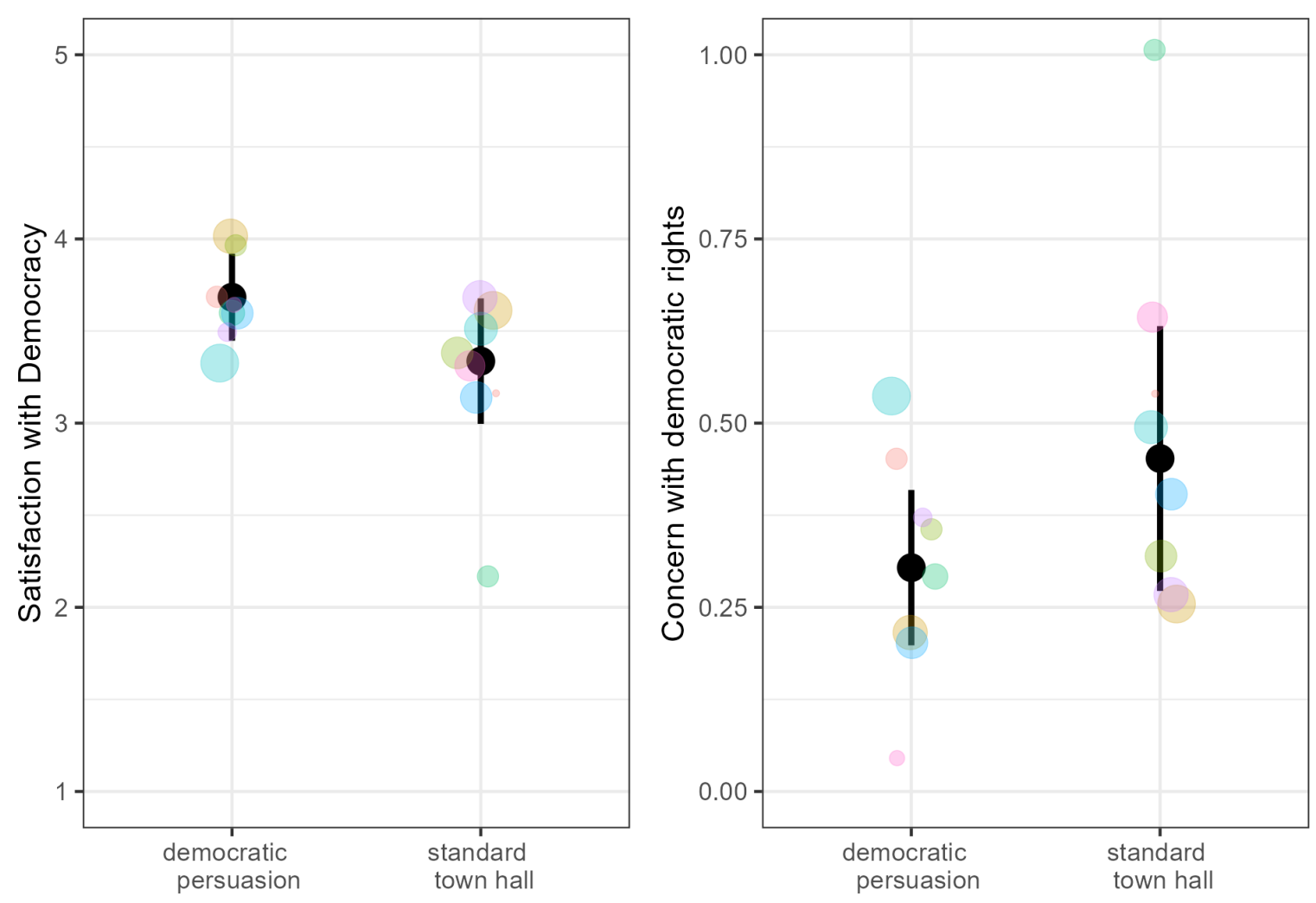

Figure 3: Treatment effects on satisfaction with democracy and concerns with democratic rights

Note: Estimated mean attitudes in both experimental conditions with 95 percent confidence intervals: bubbles in the background show cluster means for each town hall; the size of the bubble indicates townhall size; the color of the bubble is a function of experimental block, reflecting the politician who conducted the town hall; the colors have no political meaning

a democratic country (Küppers and Reiser 2021; Nachtwey, Schäfer, and Frei 2020). Without taking a stance on the merits of particular policies, our intervention deliberately sought to bolster citizens' satisfaction with the democratic process as experienced during the Covid-19 crisis, based on the idea that citizens who view this system favorably will likely see more reason to defend it against attacks.

The results show that democratic persuasion led a number of dissatisfied citizens to change their minds on democracy. Subjects who were randomly assigned to attend the democratic persuasion town hall were 0.35 points (on a 1-5 scale) more satisfied with democracy than subjects who attended the standard town halls (see Appendix 9.5 for tabulated results).$^{3}$ The effect is different from zero with $\mathrm{p}=0.03$ (unadjusted, one-sided)

\footnotetext{
${ }^{3}$ All figures show predicted mean values for each experimental condition as derived from linear regres-
} 
and 0.07 (covariate-adjusted, one-sided).

Are these meaningful effect sizes? The difference between individuals who participated in the control town halls and those who were exposed to democratic persuasion corresponds to a medium sized effect of 0.36 standard deviations. This effect size indicates a $60 \%$ chance that a subject in the treatment group reported higher satisfaction with democracy than a person in the control group (Gruijters and Peters 2017). Considering satisfaction with democracy as a binary variable, the observed effect size implies that for every 7 citizens exposed to democratic persuasion, one of them will switch from dissatisfaction to expressing satisfaction with the democratic system (Gruijters and Peters 2017). Hence, these data show that democratic persuasion has the potential to make a practical difference in how citizens think about democracy.

The right-hand panel of Figure 3 reports on another aspect of democracy's perceived legitimacy in times of existential crisis. Given the rhetoric from the political fringes that we would no longer be living in a democratic country, we measured the degree to which citizens were concerned for their democratic rights. The democratic persuasion town halls highlighted the inevitable trade-offs elected politicians faced during the pandemic. The treatment sought to alleviate concerns about the temporary restriction on civil liberties by pointing to the democratic quality of the process preceding these decisions. As a result, the share of respondents who maintained worries about their democratic rights is 15 (unadjusted) or 13 (covariate-adjusted) percentage-point lower in the treatment group, depending on specification $(\mathrm{p}=0.12 / 0.09)$.

Moreover, in the appendix we show further evidence that democratic persuasion succeeded in persuading citizens of the legitimacy of Covid-prevention measures (see Appendix Table A10), which we pre-registered as a secondary outcome. The increased support for a battery of social distancing measures indicates that we do not find any trade-off between communicating effectively about democracy and persuading citizens about the values of public health policies. In contrast, it may be the case that some citsion with standard errors clustered at the town hall level. The error bars show the $95 \%$ confidence interval surrounding the mean. The colored markers in the background display the cluster means, weighted by the number of participants in the respective cluster. Visualisation code is adapted from Coppock (2021). 

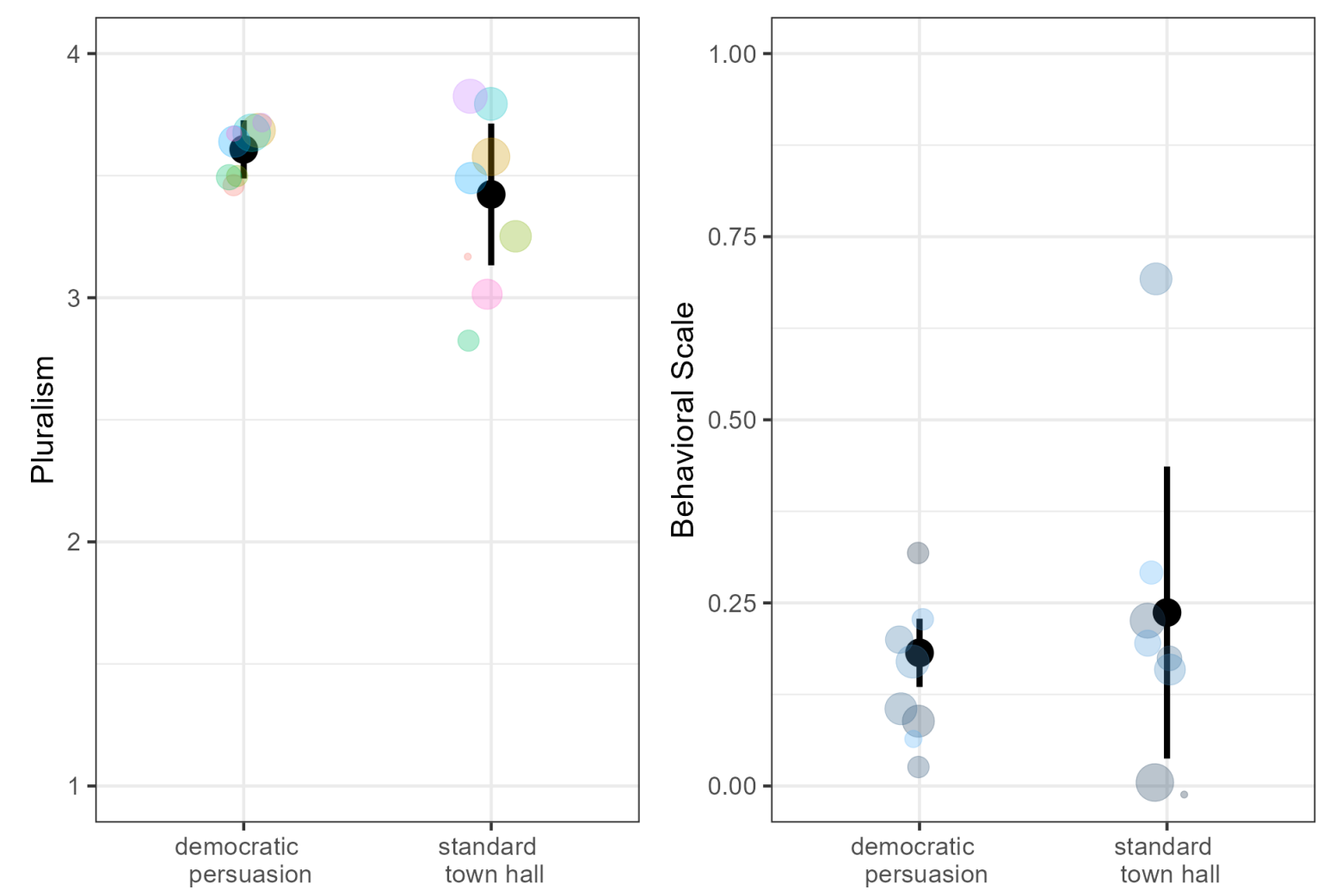

Figure 4: Treatment effects on concerns with democratic rights and on behavioral scale Note: Estimated mean attitudes in both experimental conditions with 95 percent confidence intervals; bubbles in the background show cluster means for each town hall; the size of the bubble indicates townhall size; the color of the bubble is a function of experimental block, reflecting the politician who conducted the town hall; the colors have no political meaning

izens had concerns about the social distancing measures introduced by the government, based on democratic grounds that could be alleviated when addressed by politicians.

Moving away from outcomes on the specific Covid-context, the left-hand panel of Figure 4 shows endorsement of pluralist orientations, an index capturing four statements on core ideas underpinning liberal democracy (e.g., "when making political decisions, the interests and values of different social groups often conflict with one another";" what is called a compromise in politics is just a betrayal of principles", reversed). Endorsement of these values is likely to foster commitment to the liberal-democratic political system and may ease understanding for the trade-offs that are inherent in democratic governance.

Despite reflecting deep-rooted and therefore less malleable value orientations, participants in the treatment town halls endorse pluralist values slightly more strongly, but 
the effect is estimated with considerable noise (Figure 4). On a scale from $0-4$, the endorsement of pluralist values is higher in the treatment group by 0.18 (unadjusted) or 0.1 (covariate-adjusted) scale points $(\mathrm{p}=0.07$ and $\mathrm{p}=0.11$ respectively). Exploratory analyses indicate that effects on the composite index are largely driven by democratic persuasion facilitating acknowledgment that "politicians often find themselves in a situation in which they cannot fulfill all legitimate wishes at the same time and have to balance priorities." (0.07, $\mathrm{p}=0.09$, unadjusted $)$.

Beyond attitudes we also investigate whether pro-democratic rhetoric affects behaviors. Figure 4 displays the results of our pre-registered behavioral outcome: a behavioral outcomes scale, which ranges from $0-3$ actions that subjects could take: subscribe to a democracy newsletter and sign two pro-democracy petitions. Outcomes in the two randomly assigned groups are not significantly different (see appendix 9.6 for results on single indicators results).

Democratic persuasion also had no discernible effects on the evaluation of the participating politician $(-0.01$ with $\mathrm{p}=0.48)$, a pre-registered secondary outcome. This suggests that the treatment effects reported earlier are not simply driven by higher likability perceptions of the politician in the treatment condition. In exploratory analyses, we also find no evidence that persuasion effects would differ significantly by party alignment between politician and respondent or whether the treatment was delivered by a government or by an opposition politician.

Finally, we estimate if effects decay over time. Results from a third survey wave fielded around one month after the town halls indicate that participants in the treatment group remain more likely to adequately recall that the democratic persuasion town hall focused on making the case for liberal democracy (Table 2). Moreover, there is some evidence that the positive effect on pluralistic attitudes lasted at least for one month. The long-term effect on satisfaction with democracy is significantly different from zero one month after the treatment only if we use the unadjusted CACE estimator but not for the covariate-adjusted estimate..$^{4}$

\footnotetext{
${ }^{4}$ The difference between treatment groups in wave 3 is unlikely due to differential attrition between the experimental conditions. The number of responders to survey wave 3 is not significantly different at
} 
Table 2: Effects on primary outcomes one month after the treatment

\begin{tabular}{l|r|r|r|r|r}
\hline Outcome & ITT & P-value & Cov-adj ITT & P-value & $\mathrm{N}$ \\
\hline Topic: Strengthen liberal democracy & 0.6715 & 0.0156 & 0.3759 & 0.0938 & 141 \\
\hline Satisfaction with democracy & 0.4340 & 0.0120 & 0.0900 & 0.2380 & 141 \\
\hline Pluralism & 0.2730 & 0.0510 & 0.1570 & 0.0820 & 141 \\
\hline Worried about democratic rights & -0.1380 & 0.1170 & -0.0290 & 0.6050 & 141 \\
\hline
\end{tabular}

\section{Discussion}

This study investigates the power of political elites to foster resilience of citizen commitment to democracy in times of crisis. We propose democratic persuasion as a practical, actionable intervention to strengthen the societal foundations of liberal democracy. Our field experiment provides tentative evidence that political elites can influence public opinion in favor of liberal democracy by engaging existing concerns while actively making the case for this system of government. While we observe null effects on petition signatures and newsletter sign-ups, citizens who were randomly assigned to democratic persuasion expressed higher satisfaction with democracy, more strongly endorsed pluralist values and expressed fewer concerns about their rights and about the legitimacy of public health measures relating to the Covid-19 pandemic. This experiment and all analyses were preregistered and all effects go in the hypothesized direction. Some of the observed effects are sizable. Among participants who where dissatisfied with the democratic process during the Covid-19 crisis, exposure to democratic persuasion led to a change in mind of 1 in every 7 citizens so that these citizens saw democracy in a more positive light after the town hall. Yet, as many of the estimated effects hover around the threshold of statistical significance, and as some group differences were measured with considerable noise, uncertainties remain about some of the reported findings. We opt for transparency in reporting given the importance of the topic and the value of ethical research practices. While only one of the three observed effects on democratic attitudes appear to persist one month after the treatment, we believe that, on balance, the intervention has some potential to strengthen citizen commitment to liberal democracy in times of crisis. How72 in the standard town hall and 69 in the democratic persuasion town hall. 
ever, for attitudinal change to be sustained, democratic persuasion would need to become a routine practice in how pro-democracy legislators communicate with citizens.

Although we worked together with legislators from five different political parties who represent citizens at different levels of government, we have only investigated democratic persuasion in one country, Germany, and at one point in time. From a theoretical point of view, we expect the results to generalize to similar contexts, where citizens have experienced democracy for a sustained period of time, but where the liberal democratic system is under pressure from political entrepreneurs that try to exploit apparent shortcomings by denying trade-offs and spreading misinformation. For this intervention to scale, it assumes that citizens generally hold pro-democratic predispositions and that a majority of political elites are not actively undermining or attacking the system. It therefore remains an open question whether the observed effects generalize to context such as the United States, where politicians affiliated with one of the two main political parties regularly question the foundations of liberal democracy. We have explored democratic persuasion in the context of direct encounters between politicians and citizens but much of its untapped potential lies in mediated communication (e.g., Clayton and Willer (2021); Wuttke, Sichart, and Foos (2022)). A next step could be to explore how mass endorsement of democracy would change if politicians spend only some of their time during interviews, parliamentary speeches or televized debates to actively make the case for democracy.

In this experiment, we privileged the authenticity of the intervention and the ecological validity of the online town hall setting over an ability to disentangle every aspect of democratic persuasion. Survey or lab experimental settings provide more control over the administration of and compliance with interventions. Hence, in more controlled settings, future research could disentangle in greater detail the effects of different types of persuasive messages on citizen commitment to democracy. Experiments with larger sample sizes could also test whether particular messages are more effective in specific segments of the population. Overall, our hope is that this study serves as a catalyst for a research agenda that leverages academic insights to devise practical interventions that 
can help secure the societal foundations of liberal democracy.

Our argument for democratic persuasion as a non-judgmental rhetorical strategy is based on the assertion that existing doubts and discontent often have at least some foundation in political and social reality. That means political communication can clarify misconceptions or highlight principles and trade-offs that were not apparent to citizens who do not spend their days thinking about the complexities of political institutions and processes. If politicians who support the liberal democratic system fail to act, the stage is left to political entrepreneurs who attempt to seize upon concerns and anxieties of citizens and turn them against the liberal-democratic order. Highlighting the potential value of democratic persuasion does not mean that political actors should abandon issue-based or election-driven persuasion as a goal, but they might engage in democratic persuasion alongside it. Since we do not find any apparent trade-off between democratic persuasion and issue-based persuasion (on social distancing measures), and no negative effects on trust in the representative, there are few draw-backs of engaging in this communicative strategy. At the same time, for a resilient democratic culture, political communication can only ever be one of many strategies that pro-democracy actors can pursue, others being the defense and strengthening of formal democratic institutions and delivery on policy commitments that benefit a majority of citizens (Pappas 2019; Diamond 2020; Runciman 2018).

In a time when democracy is under pressure, it is worth recalling that an act of democratic persuasion stood at the outset of the American experiment of self-governance. The federalist papers were a document of political theory but also the deliberate attempt of political leaders to convince a hesitant public of the value of a republican constitution. Likewise, in Germany after the experiences of Nazism, the Holocaust and defeat in WW2, political science was refounded as democracy science to act on the insight that democracy cannot be taken for granted and that academics have a responsibility to promote democratic ideas among the citizenry (Zeuner 1989). Now that liberal democracy has come under pressure again, as academics, it is worth taking up the tradition of political science as democracy science; and for political and social elites with some communicative 
power, it is worth taking up the tradition of democratic persuasion. 


\section{References}

Abernathy, Claire, Kevin M. Esterling, Justin Freebourn, Ryan Kennedy, William Minozzi, Michael A. Neblo, and Jonathan A. Solis. 2019. "Constituent Communication Through Telephone Town Halls: A Field Experiment Involving Members of Congress." Legislative Studies Quarterly 44 (4): 617-46. https://doi.org/10. 1111/lsq.12242.

Altay, Sacha, Marlène Schwartz, Anne-Sophie Hacquin, Aurélien Allard, Stefaan Blancke, and Hugo Mercier. 2022. "Scaling up Interactive Argumentation by Providing Counterarguments with a Chatbot." Nature Human Behaviour 6 (4): 579-92. https: //doi.org/10.1038/s41562-021-01271-w.

Amat, Francesc, Andreu Arenas, Albert Falcó-Gimeno, and Jordi Muñoz. 2020. "Pandemics Meet Democracy. Experimental Evidence from the COVID-19 Crisis in Spain," April. https://doi.org/10.31235/osf.io/dkusw.

Arceneaux, Kevin, Bert N. Bakker, Sara Hobolt, and Catherine Eunice De Vries. 2020. "Is COVID-19 a Threat to Liberal Democracy?" http://dx.doi.org/10.31234/ osf.io/8e4pa.

Becher, Michael, Nicolas Longuet Marx, Vincent Pons, Sylvain Brouard, Martial Foucault, Vincenzo Galasso, Eric Kerrouche, Sandra León Alfonso, and Daniel Stegmueller. 2021. "COVID-19, Government Performance, and Democracy: Survey Experimental Evidence from 12 Countries." https://doi.org/10.3386/w29514.

Bermeo, Nancy. 2016. "On Democratic Backsliding." Journal of Democracy 27 (1): 5-19. https://doi.org/10.1353/jod.2016.0012.

—. 2020. "Ordinary People in Extraordinary Times," June. https://doi.org/10. $2307 /$ j.ctv10h9d4p.

Bor, Alexander, Frederik Juhl Jørgensen, and Michael Bang Petersen. 2021. "The COVID-19 Pandemic Eroded System Support but Not Social Solidarity." http: //dx.doi.org/10.31234/osf.io/qjmct.

Brettschneider, Corey. 2010. "When the State Speaks, What Should It Say? The Dilemmas of Freedom of Expression and Democratic Persuasion." Perspectives on Politics 
8 (4): 1005-19. https://doi.org/10.1017/S1537592710003154.

Broockman, David, and Joshua Kalla. 2016. "Durably Reducing Transphobia: A Field Experiment on Door-to-Door Canvassing." Science 352 (6282): 220-24. https: //doi.org/10.1126/science.aad9713.

Cantoni, Enrico, and Vincent Pons. 2021. "Do Interactions with Candidates Increase Voter Support and Participation? Experimental Evidence from Italy." Economics 8 Politics 33 (2): 379-402.

Clayton, Katherine, and Robb Willer. 2021. "Endorsements from Republican Politicians Can Increase Confidence in U.S. Elections." SSRN Electronic Journal. https://doi. org/10.2139/ssrn.3961104.

Coppock, Alexander. 2021. "Visualize as You Randomize: Design-Based Statistical Graphs for Randomized Experiments." In Advances in Experimental Political Science, edited by James Druckman and Donald P.Editors Green, 320-36. Cambridge University Press. https://doi.org/10.1017/9781108777919.022.

Daniele, Gianmarco, Andrea Martinangeli, Francesco Passarelli, Willem Sas, and Lisa Windsteiger. 2020. "Wind of Change? Experimental Survey Evidence on the Covid19 Shock and Socio-Political Attitudes in Europe." SSRN Electronic Journal. https: //doi.org/10.2139/ssrn.3671674.

De Vries, Catherine E., and Sara B. Hobolt. 2020. "Political Entrepreneurs." https: $/ /$ doi.org/10.2307/j.ctvt9k3d3.

Diamond, Larry Jay. 2020. Ill Winds: Saving Democracy from Russian Rage, Chinese Ambition, and American Complacency. https://ebookcentral.proquest.com/lib/ tufts-ebooks/detail.action?docID $=6062979$.

Finkel, Steven, Junghyun Lim, Anja Neundorf, Aykut Öztürk, and Daniel Shephard. 2022. "Democratic Citizenship Through Adult Civic Education? A Systematic Review and Pre-Meta-Analysis." http://dx.doi.org/10.31219/osf.io/427gh.

Finkel, Steven, Anja Neundorf, and Ericka Gabriela Rascon Ramirez. 2021. "Can Online Civic Education Induce Democratic Citizenship? Experimental Evidence from a New Democracy." SSRN Electronic Journal. https://doi.org/10.2139/ssrn.3778600. 
Foa, Roberto, A. Klaasen, M. Slade, and Collins Rand A. 2020. "The Global Satisfaction with Democracy Report 2020." Centre for the Future of Democracy. https://www. bennettinstitute.cam.ac.uk/publications/global-satisfaction-democracy-report$2020 /$.

Foos, Florian. 2018. "The Parliamentary Candidate as Persuader: Evidence from Randomized Candidate-Voter Interactions." Working Paper. http://www.florianfoos. net/resources/Candidate_as_persuader_Foos.pdf.

"German General Social Survey - ALLBUS 2018." 2019. GESIS Data Archive. https: //doi.org/10.4232/1.13325.

Gibson, James L. 1998. "A Sober Second Thought: An Experiment in Persuading Russians to Tolerate." American Journal of Political Science 42 (3): 819. https: //doi.org/10.2307/2991731

Graham, Matthew H., and Milan W. Svolik. 2020. "Democracy in America? Partisanship, Polarization, and the Robustness of Support for Democracy in the United States." American Political Science Review 114 (2): 392-409. https://doi.org/10. $1017 / \mathrm{s} 0003055420000052$.

Gruijters, Stefan L.K., and Gjalt Peters. 2017. "Gauging the Impact of Behavior Change Interventions: A Tutorial on the Numbers Needed to Treat." http://dx.doi.org/ 10.31234/osf.io/2bau7.

Guess, Andrew M, Brendan Nyhan, Zachary O'Keeffe, and Jason Reifler. 2020. "The Sources and Correlates of Exposure to Vaccine-Related (Mis) Information Online." Vaccine 38 (49): 7799-7805.

Guess, Andrew M, Brendan Nyhan, and Jason Reifler. 2020. "Exposure to Untrustworthy Websites in the 2016 US Election." Nature Human Behaviour 4 (5): 472-80.

Hobolt, Sara B., and Moritz Osnabrügge. 2022. "Countering Authoritarian Behavior in Democracies." Working Paper.

Jungherr, Andreas, Gonzalo Rivero, and Daniel Gayo-Avello. 2020. "Retooling Politics," June. https://doi.org/10.1017/9781108297820.

Kalla, Joshua L., and David E. Broockman. 2020. "Reducing Exclusionary Attitudes 
Through Interpersonal Conversation: Evidence from Three Field Experiments." American Political Science Review 114 (2): 410-25. https://doi.org/10.1017/s0003055419000923.

Kirsch, Helen, and Christian Welzel. 2018. "Democracy Misunderstood: Authoritarian Notions of Democracy Around the Globe." Social Forces 98 (1): 59-92. https: //doi.org/10.1093/sf/soy114

Kolvani, Palina, Martin Lundstedt, Amanda B. Edgell, and Jean Lachapelle. 2021.

"Pandemic Backsliding: A Year of Violations and Advances in Response to Covid19." https://www.v-dem.net/media/filer_public/77/15/7715745a-d5a4-4a9fa8be-75ec0ac5d19a/pb_32.png.

Küppers, Anne, and Marion Reiser. 2021. "'It Is Not Worse Than a Flu'-COVID-19 Scepticism and the Role of Trust and Far-Right Attitudes in Germany."

Lenz, Gabriel S. 2012. Follow the Leader?: How Voters Respond to Politicians' Policies and Performance. Chicago ; London.

Linz, Juan J. (Juan Jose), and Alfred C. Stepan. 1996. "Toward Consolidated Democracies." Journal of Democracy 7 (2): 14-33. https://doi.org/10.1353/jod.1996. 0031 .

Lipset, Seymour. 1981. Political Man : The Social Bases of Politics. Baltimore: Johns Hopkins University Press.

López-Moctezuma, Gabriel, Leonard Wantchekon, Daniel Rubenson, Thomas Fujiwara, and Cecilia Pe Lero. 2020. "Policy Deliberation and Voter Persuasion: Experimental Evidence from an Election in the Philippines." American Journal of Political Science. Lührmann, Anna, and Staffan I Lindberg. 2019. "A Third Wave of Autocratization Is Here: What Is New about It?" Democratization 26 (7): 1095-1113.

Minozzi, William, Michael A. Neblo, Kevin M. Esterling, and David M. J. Lazer. 2015. "Field Experiment Evidence of Substantive, Attributional, and Behavioral Persuasion by Members of Congress in Online Town Halls." Proceedings of the National Academy of Sciences 112 (13): 3937-42. https://doi.org/10.1073/pnas.1418188112. Müller, Jan-Werner. 2021. Democracy Rules. Penguin Books Ltd (UK). https://www. ebook.de/de/product/39568126/jan_werner_mueller_democracy_rules.html. 
Muradova, Lala. 2021. "Seeing the Other Side? Perspective-Taking and Reflective Political Judgements in Interpersonal Deliberation." Political Studies 69 (3): 644-64. https://doi.org/10.1177/0032321720916605.

Mvukiyehe, Eric, and Cyrus Samii. 2017. "Promoting Democracy in Fragile States: Field Experimental Evidence from Liberia." World Development 95 (July): 254-67. https://doi.org/10.1016/j.worlddev.2017.02.014.

Nachtwey, Oliver, and Nadine Frei. 2021. "Quellen Des Querdenkertums. Eine Politische Soziologie Der Corona-Proteste in Baden-Württemberg." Heinrich Böll Stiftung.

Nachtwey, Oliver, Robert Schäfer, and Nadine Frei. 2020. "Politische Soziologie der Corona-Proteste." https://doi.org/10.31235/osf.io/zyp3f.

Nyhan, Brendan. 2020. "Facts and Myths about Misperceptions." Journal of Economic Perspectives 34 (3): 220-36. https://doi.org/10.1257/jep.34.3.220.

Pappas, Takis S. 2019. Populism and Liberal Democracy: A Comparative and Theoretical Analysis. Oxford.

Runciman, David. 2018. Runciman, d: How Democracy Ends. London.

Saikkonen, Inga, and Henrik Serup Christensen. 2021. "Guardians of Democracy or Passive Bystanders? A Conjoint Experiment on Elite Transgressions of Democratic Norms." http://dx.doi.org/10.31235/osf.io/j6tvy.

Schraff, Dominik. 2020. "Political Trust During the Covid-19 Pandemic: Rally Around the Flag or Lockdown Effects?" European Journal of Political Research, November. https://doi.org/10.1111/1475-6765.12425.

Skaaning, Svend-Erik. 2021. "Democracy: Contested Concept with a Common Core." In, edited by Gordon Crawford and Adulai Abdul-Gafaru, 27-44. Edward Elgar Publishing.

Stenner, Karen. 2005. "The Authoritarian Dynamic," July. https://doi.org/10.1017/ cbo9780511614712.

Valgarðsson, Viktor Orri, and Daniel Devine. 2021. "What Satisfaction with Democracy? A Global Analysis of "Satisfaction with Democracy" Measures." Political Research Quarterly, May, 106591292110096. https://doi.org/10.1177/10659129211009605. 
V-DEM. 2020. "Defending Democracy Against Illiberal Challengers." V-DEM Institute. https://www.v-dem.net/media/filer_public/f3/f0/f3f09467-bcf7-4f8a-9ad9. e83171673705/v-dem_resourceguide_20-05-28_final-better.pdf.

Wantchekon, Leonard. 2017. "Policy Deliberation and Voter Persuasion: Estimating Intrinsic Causal Effects of Town Hall Meetings." Journal of Development Effectiveness 9 (3): 295-304. https://doi.org/10.1080/19439342.2017.1349165.

Wunsch, Natasha, Marc Jacob, and Laurenz Derksen. 2022. "The Demand Side of Democratic Backsliding: How Divergent Understandings of Democracy Shape Political Choice."

Wuttke, Alexander, Konstantin Gavras, and Harald Schoen. 2020. "Have Europeans Grown Tired of Democracy? New Evidence from Eighteen Consolidated Democracies, 1981-2018." British Journal of Political Science, October, 1-13. https://doi.org/ $10.1017 / \mathrm{s} 0007123420000149$

Wuttke, Alexander, Florian Sichart, and Florian Foos. 2022. "Null Effects of ProDemocracy Speeches by u.s. Republicans in the Aftermath of January 6th." http: //dx.doi.org/10.31235/osf.io/pd5za.

Xu, Mengran, and Richard E. Petty. 2021. "Two-Sided Messages Promote Openness for Morally Based Attitudes." Personality and Social Psychology Bulletin, February, 014616722098837. https://doi.org/10.1177/0146167220988371.

Zaller, John R. 1992. "The Nature and Origins of Mass Opinion," August. https: //doi.org/10.1017/cbo9780511818691.

Zeuner, Bodo. 1989. "Politikwissenschaft Als Demokratiewissenschaft — Ein Vergessener Anspruch?" In, 128-42. VS Verlag für Sozialwissenschaften. https://doi.org/10. 1007/978-3-322-84139-1_9. 


\section{$9 \quad$ Appendix}

\section{Appendix: Table of content}

- Attitudes towards democracy

- Respondents' choice of townhalls

- Questionnaire

- Deviations from pre-analysis plan

- Primary Outcomes

- Behavioral scale

- Ethical considerations

- Comparison to general population

- Balance and randomization

- Secondary Outcomes

- Effect heterogeneity

- Link to anonymized PAP

Online Repository The Online Repository (link to be added upon acceptance) associated with this article contains:

- Pre-registration plans

- Reproduction material

- Questionnaires

- The stimulus slides we used in the democratic persuasion town halls

- Unipark files to import W1 and W3 survey waves in Questback/ Unipark/ Tivian 


\subsection{Attitudes towards democracy: Sampling and prior attitudes}

The V-DEM Resource guide for sustaining democracy (V-DEM 2020) characterizes 'wavering democrats' as potentially susceptible to democratic persuasion. The group of wavering democrats comprises those segments of the population whose attitudes on democracy lie between anti-democratic extremists and satisfied democrats. Wavering democrats express concerns about democratic politics or democratic principles but have not yet given up on the democratic idea altogether. Therefore, in recruiting a sample for the experiment, we pursuit the goal of reaching a sizable number of wavering democrats.

Another aspect of our sampling recruitment strategy also followed from the V-DEM Resource guide for sustaining democracy (V-DEM 2020). We made the deliberate choice to exclude militant anti-democrats from the town hall meetings. During the recruitment survey, we filtered out respondents who met the following criteria:

- Strongly agreed that the government is hiding important information on the Covid19 pandemic AND

- Strongly agreed that democracies are weak in making decisions AND

- Strongly disagreed that democracy may have its problem but is better than any other form of government.

We filtered out 6 survey respondents with this combination of attitudes who therefore were not invited to the town hall meetings. While we generally encouraged critical debate, we presumed that militant anti-democrats might have impoverished the discussion climate. We further believed that attempts of democratic persuasion might be futile among this group of citizens. We thus excluded militant anti-democrats.

To assess the participants' pre-treatment attitudes, the table below reports the participants' stances on democracy and the government's handling of the Covid-19 pandemic. All attitudes were measured before the respondents participated in the town hall meetings. Variables are coded so that higher values indicate higher support for the current democratic order.

The vast majority of respondents supports the idea of self-governance. Considering democracy as the best form of government is an almost universally held position among the participants. Hence, attitudes towards the democratic system are overwhelmingly positive when queried on an abstract level which is in line with existing public opinion research (Wuttke, Gavras, and Schoen 2020). Still, some respondents endorse populist views on politics and some respondents do not fully support pluralist principles. But these views are only held by minorities. Yet, when it comes to the specifics of democratic practice, negative evaluations of democracy are not confined to small segments of the population. In the context of Covid-19, dissatisfaction with democracy was widespread. Hence, we succeeded in recruiting a sample including a sizable number of citizens who held concerns about democratic principles and the democratic process.

Against the backdrop of the Covid-19 pandemic, one important predictor of attitudes towards the democratic system are citizen perceptions' of how the government handles the pandemic. The data show ample variation in attitudes towards Covid-politics. Some respondents were very satisfied and and some were very dissatisfied with the government's handling of the pandemic. We also observe notable variation across the entire response scale on whether respondents feel concerned about the infringement of their democratic 
Table A1: Pre-treatment attitudes

\begin{tabular}{|c|c|c|c|c|c|}
\hline & Min & $\operatorname{Max}$ & Mean & Histogram & Boxplot \\
\hline Trust in Covid Politics & 1 & 5 & 2.47 & $" 1$ & Ппに \\
\hline Gov is hiding info on Covid (r) & 1 & 5 & 3.33 & $\vdash 1$ & له \\
\hline Covid policies: Harm outweighs good (r) & 1 & 7 & 4.73 & +11 & 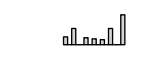 \\
\hline Concerned about democratic rights $(\mathrm{r})$ & 1 & 5 & 2.64 & $1-$ & 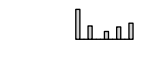 \\
\hline Satisfaction with democracy & 1 & 5 & 3.09 & •-1 & 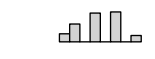 \\
\hline Pluralism & 1 & 4 & 3.34 & $\cdot \vdash$ & ] لمهـ \\
\hline Populist attitudes (r) & 0 & 12 & 5.61 & レー・・ & مس7ח \\
\hline Democracy: best form to govern & 1 & 5 & 4.65 & $\cdots \curvearrowleft 1$ & لمـ \\
\hline Democracy: weak decisions $(\mathrm{r})$ & 1 & 5 & 4.07 & 一1, & لمهــ \\
\hline Democracy: cannot maintain order $(r)$ & 1 & 5 & 4.19 & $\cdots \mapsto$ & 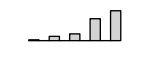 \\
\hline
\end{tabular}

rights. Moreover, a substantial share of participants agrees with the conspiratorial notion that "the government is hiding important information on the Covid-19 pandemic". All things considered, with regards to the Covid-19-pandemic and its ramifications for democracy, our sampling strategy succeeded in recruiting a sizable group of respondents with critical and very critical attitudes to democracy or democracy's response to the Covid-19 pandemic.

\subsection{Respondents' choice of town halls}

When signing up to our academic study and the town hall meeting, respondents could choose which town hall to attend. For each town hall on a particular date, respondents were given the name of the participating politician along with the location of the politician's electoral district. Respondents were blinded as to whether a town hall would feature democratic persuasion or not. Even though no information was given on the party affiliation of the politicians, participants might have known or looked up which parties the politicians belonged to and participants might have been more likely to sign up for liked-minded politicians.

To test whether respondents were evenly distributed among town hall meetings, we examine how party identifiers self-selected into town hall meetings. Examining all respondents who signed up for a town hall meeting, Table A2 shows the number and share of party identifiers in each town hall meeting, grouped by the party affiliation of the participating politician. The table shows some, but no strong selection into town halls, based on which party the legislator belonged to. It is important to emphasize that these selection effects are orthogonal to treatment assignment, since participants did not know if they attended a democratic persuasion or a standard town hall. 
Table A2: Choice of town hall by PID

\begin{tabular}{lccccc}
\hline Characteristic & CDU $/ \mathrm{CSU}, \mathrm{N}=62$ & $\mathrm{SPD}, \mathrm{N}=172$ & FDP, N =109 & Left, N = 118 & Greens, N =68 \\
\hline Party ID, n (\%) & $9(31 \%)$ & $6(8.0 \%)$ & $7(16 \%)$ & $5(9.3 \%)$ & $1(2.9 \%)$ \\
CDU/CSU & $2(6.9 \%)$ & $22(29 \%)$ & $4(9.1 \%)$ & $7(13 \%)$ & $6(18 \%)$ \\
SPD & $0(0 \%)$ & $3(4.0 \%)$ & $2(4.5 \%)$ & $2(3.7 \%)$ & $0(0 \%)$ \\
AfD & $5(17 \%)$ & $6(8.0 \%)$ & $9(20 \%)$ & $6(11 \%)$ & $2(5.9 \%)$ \\
FDP & $2(6.9 \%)$ & $11(15 \%)$ & $4(9.1 \%)$ & $13(24 \%)$ & $8(24 \%)$ \\
Left & $6(21 \%)$ & $15(20 \%)$ & $13(30 \%)$ & $14(26 \%)$ & $14(41 \%)$ \\
Greens & $5(17 \%)$ & $12(16 \%)$ & $5(11 \%)$ & $7(13 \%)$ & $3(8.8 \%)$ \\
other & & & &
\end{tabular}




\subsection{Questionnaire}

Here we list the question wordings of the outcome measures in wave 2. The questionnaire was implemented via Zoom poll. The complete wave 1, wave 2 and wave 3 questionnaires in German and English will be made available as Supplementary Material upon acceptance.

Covid measures Various measures are being discussed in Germany to contain the Covid-19 pandemic. We would now like to know from you what you think of the measures that have already been decided and of possible future measures. Which of the following measures do you consider appropriate in the current situation?

(A) Closure of public institutions (e.g. universities, schools and kindergartens)

(B) Prohibition of demonstrations in which the minimum distance is not observed

(C) Mask requirement in public spaces

(D) General contact limitations

(E) Postpone elections until the pandemic is over

(F) I do not consider any of these measures to be appropriate in the current situation.

Trust government on Covid Do you trust the government's strategy in the Covid pandemic?

(1) do not trust at all

(2) tend not to trust

(3) partly

(4) mostly trust

(5) trust fully

Trust politician To what degree did you get the impressions you could trust the member of parliament in this town hall meeting?

(1) do not trust at all

(2) tend not to trust

(3) partly

(4) mostly trust

(5) trust fully 
Populism and democracy Here are some political and social statements that some people agree with and others disagree. Please select all statements you fully agree with.

(A) Under the current circumstances I am concerned for my democratic rights.

(B) Democracy may have problems but it is definitely better than any other form of government.

(C) Most politicians don't care much about what people like me think. (Anti-elitism)

(D) The people, not the politicians, should make the most important political decisions. (Sovereignty)

(E) The Germans are a cohesive unit and not just a bunch of individual people. (Homogeneity)

(F) I do not agree with any of these statements

Satisfaction with democracy On the whole, how satisfied or dissatisfied are you with the way democracy works in Germany?

(1) very satisfied

(2) fairly satisfied

(3) neither satisfied nor dissatisfied

(4) not very satisfied

(5) not at all satisfied

Pluralism For a last time, we are interested in your political opinion. Please select all statements you agree with.

Politicians often find themselves in a situation in which they cannot fulfill all legitimate wishes at the same time and have to balance priorities.

Political decisions are above all a choice between good and bad.

When making political decisions, the interests and values of different social groups often conflict with one another.

What is called a compromise in politics is just a betrayal of principles.

I do not agree with any of these statements.

Manipulation check To conclude: What was particularly important to the member of parliament and the organizers of the town hall meeting?

- Stressing that the Covid-19 Virus is airborne

- Look at political issues from multiple perspective and balance them

- Step up for the value of liberal democracy

- Stressing the laudable role of Germany's Covid-19 policies

- None of the statements apply 


\subsection{Deviations from pre-analysis plan}

For this study, we pre-registered the theoretical arguments, hypotheses, power analysis and the analysis syntax (see Appendix 9.12 for an anonymized copy). Here, we document and explain deviations from the pre-analysis plan and other peculiarities.

Updated pre-analysis plan The original pre-analysis plan with hypotheses, analysis syntax and power analysis was pre-registered on Nov 16th before the first town hall meeting was conducted. A few days later, we noticed minor mistakes in the analysis syntax and registered an updated pre-analysis file in the same project with no changes other than the following:

- coding errors that prohibited the markdown file from rendering were fixed

- we have added a regional dummy (east/west) as additional covariate

- corrected the direction of one one-sided hypothesis test that had been coded in reverse

Outcome: trust in politician Due to last-minute changes to the pre-analysis plan there is an inconsistency in the list of primary outcomes in the registered material. The verbal pre-registration plan (.rmd, .pdf) lists "trust in politician" as a primary outcome and it is mentioned in the pre-registered hypothesis. Yet, this variable was removed as primary outcome from the pre-registered analysis script.

We decided not to report this variable as primary outcome prominently in the main text but we report inline results in the main text. Substantively, the variable is not closely related to our main research question on citizen commitment to democracy. The estimated treatment effect of democratic persuasion on trust in the politician who attended the respective town hall meeting is -0.01 with $\mathrm{p}=0.484$.

Town hall hypothesis The pre-analysis plan lists two types of hypotheses. The democratic persuasion hypothesis (formerly labelled democratic talk hypothesis) and town hall hypotheses. The former refers to effects of the experimental stimulus (democratic persuasion). The latter refers to participation in the town hall per se. We suspected that participation in the town halls could on its own strengthen citizen commitment to democracy and support for the government's Covid-19 response.

As stated in the PAP's abstract, our primary interest for this project concerned the effects of our experimental manipulation to assess whether democratic persuasion is a viable means to strengthen citizen commitment to democracy. Yet, we also pre-registered analyses on whether participation in the town halls per se might have effects on citizen attitudes, irrespective of whether democratic persuasion was employed or not. However, our project is not designed to answer this question which is why in the PAP we declared this question as being of secondary interest ("The causal identification strategy for the town hall effect requires additional assumptions compared to the democratic talk hypothesis, namely the no time-variant confounder assumption usually imposed in panel studies. Therefore, we consider results on the town hall effects as secondary.")

The main problem regarding our identification strategy for the town hall effects is that attitudinal changes between survey waves 1 and 2 may reflect effects of the town halls but they may also reflect any other influence (e.g. political events) that affected participants' attitudes between the survey waves. This is particularly problematic as our 
town hall meetings took place in the midst of the second Covid-19 wave. The second wave might have influenced attitudes towards democracy and the government's Covid-response because it was widely believed that the government reacted too late to the burgeoning wave of new cases. Hence, it is unlikely that the town hall meetings were the only relevant event that may have shaped attitudes between survey waves. As a consequence, from the given data it is impossible to disentangle the various factors that underlie the observed dynamics in attitudes. We decided not to report results on the town hall effects in the main text but report the results in Appendix 9.11. 


\subsection{Primary outcomes}

Table A3 tabulates the effects (reported visually in the main text) on the primary outcomes. The first row reports results on the manipulation check.

Table A3: Primary Outcomes

\begin{tabular}{l|r|r|r|r|r}
\hline Outcome & ITT & P-value & Cov-adj ITT & P-value & N \\
\hline Topic: Strengthen liberal democracy & 0.265 & 0.004 & 0.243 & 0.004 & 185 \\
\hline Satisfaction with democracy & 0.347 & 0.031 & 0.217 & 0.066 & 185 \\
\hline Pluralism & 0.185 & 0.070 & 0.099 & 0.105 & 185 \\
\hline Worried about democratic rights & -0.148 & 0.117 & -0.131 & 0.086 & 185 \\
\hline
\end{tabular}

Table A4 shows entire regression tables for the primary outcomes using lm_robust from the estimatr package. Note that, as pre-registered, in the main text we compute treatment effects using randomization inference from the estimatr package but this method only outputs treatment effects and no information on the included covariates. Here, we report results using the $1 \mathrm{~m}$ _robust function from the same package to give information on the associations between outcomes and covariates that were included in analysis. Table A4 shows standardized regression coefficients and standard errors.

Table A4: Regression tables

\begin{tabular}{l|r|r|r|r|r|r}
\hline Variable & Stsfctn & Stsfctn SE & Plur Est. & PlurSE & Dem Rights & Dem Rights SE \\
\hline Intercept & 1.708 & 0.389 & 2.378 & 0.563 & 0.856 & 0.230 \\
\hline Treatment & 0.249 & 0.125 & 0.094 & 0.070 & -0.148 & 0.082 \\
\hline Pre_Score & 0.583 & 0.090 & 0.356 & 0.079 & -0.212 & 0.088 \\
\hline Age Group 2 & 0.298 & 0.264 & -0.201 & 0.139 & 0.031 & 0.279 \\
\hline Age Group 3 & 0.217 & 0.326 & -0.215 & 0.224 & 0.132 & 0.090 \\
\hline Age Group 4 & 0.694 & 0.245 & -0.192 & 0.290 & 0.123 & 0.087 \\
\hline Age Group 5 & 0.466 & 0.295 & -0.213 & 0.138 & 0.007 & 0.121 \\
\hline Age Group 6 & 0.490 & 0.271 & -0.280 & 0.098 & 0.035 & 0.186 \\
\hline Uni & 0.681 & 0.219 & -0.458 & 0.450 & -0.070 & 0.031 \\
\hline Left-Right & -0.241 & 0.240 & 0.084 & 0.227 & 0.042 & 0.048 \\
\hline East & -0.194 & 0.158 & 0.009 & 0.042 & 0.028 & 0.174 \\
\hline Pid 1 & -0.016 & 0.030 & -0.031 & 0.191 & 0.064 & 0.134 \\
\hline Pid 2 & 0.102 & 0.294 & 0.121 & 0.138 & 0.112 & 0.140 \\
\hline Pid 3 & -0.524 & 0.302 & -0.239 & 0.206 & 0.021 & 0.120 \\
\hline Pid 4 & -0.211 & 0.358 & -0.301 & 0.260 & 0.051 & 0.117 \\
\hline Pid 5 & -0.545 & 0.356 & -0.313 & 0.226 & 0.160 & 0.125 \\
\hline Pid 6 & -0.253 & 0.325 & -0.010 & 0.137 & 0.209 & 0.088 \\
\hline Pid 7 & -0.255 & 0.426 & -0.050 & 0.249 & 0.110 & 0.025 \\
\hline
\end{tabular}

All analyses reported in the main text were conducted using randomization inference by the ri2 package. Here we report he randomization inference plots that show the results on testing whether we can reject the sharp null hypothesis of no positive effect for any subject, using the unadjusted models. 


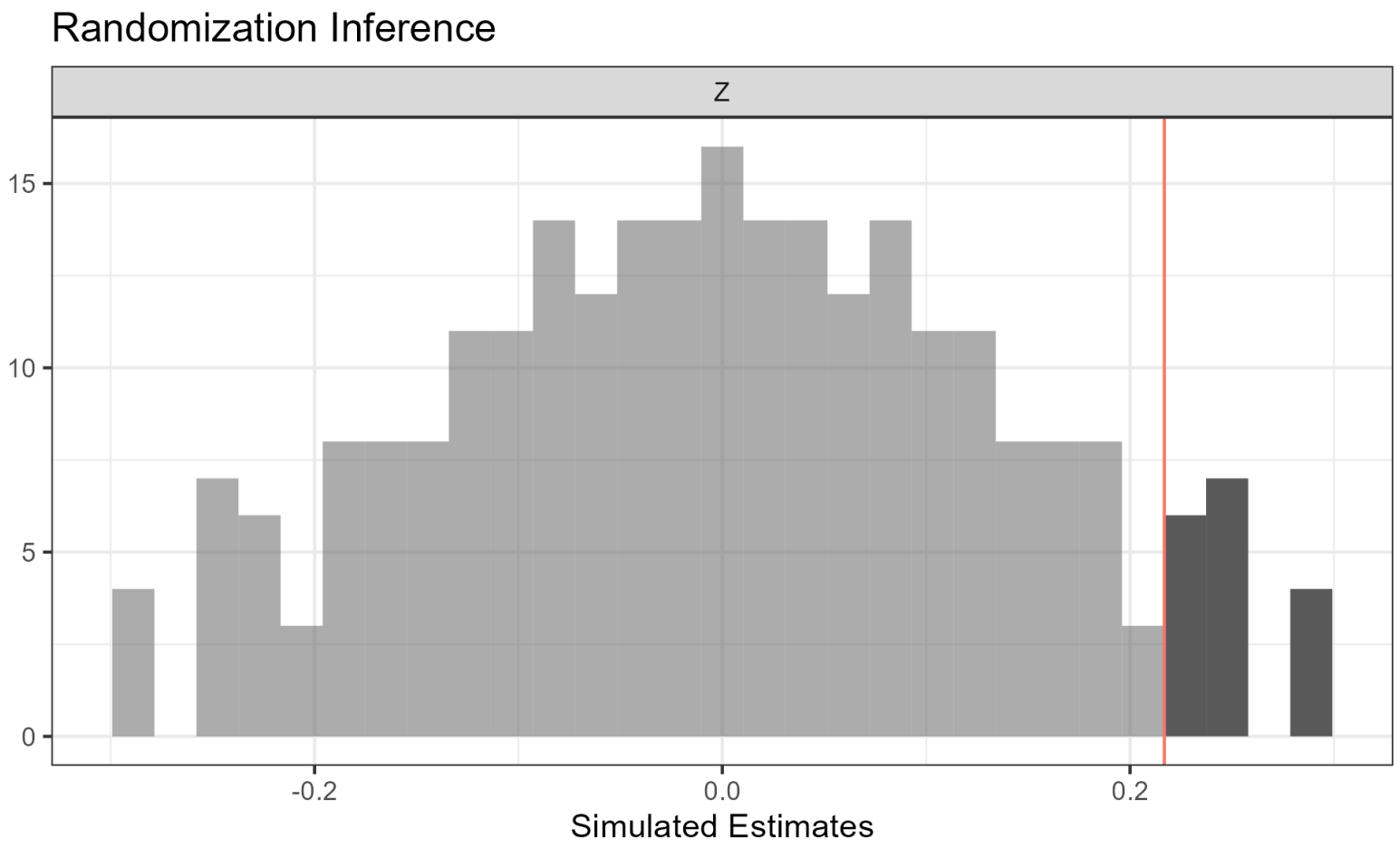

\begin{tabular}{l|l} 
Estimate & Observed Value
\end{tabular}

Figure A5: Effects on satisfaction with democracy

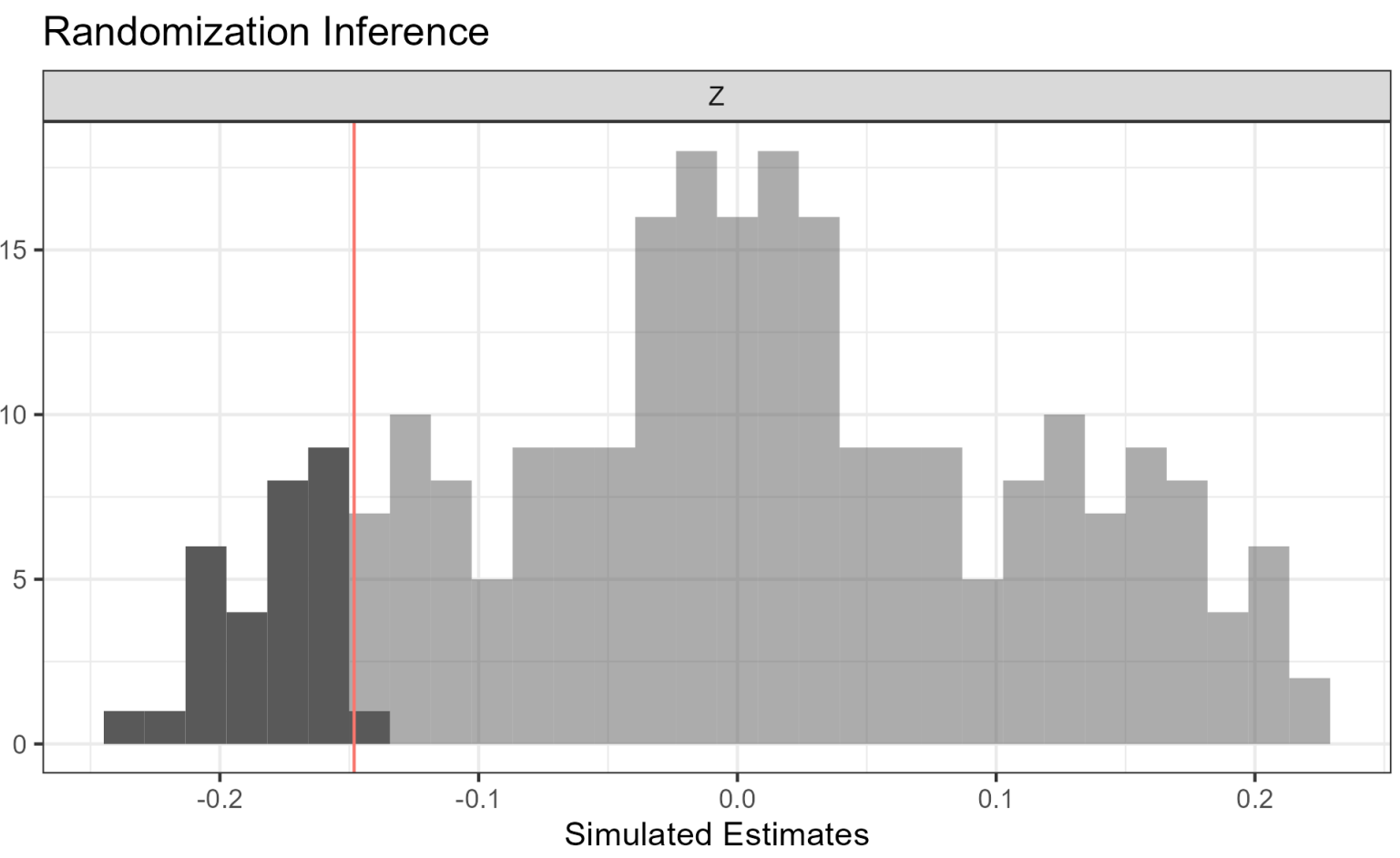

Estimate $\quad$ Observed Value

Figure A6: Effects on concerns with democratic rights 


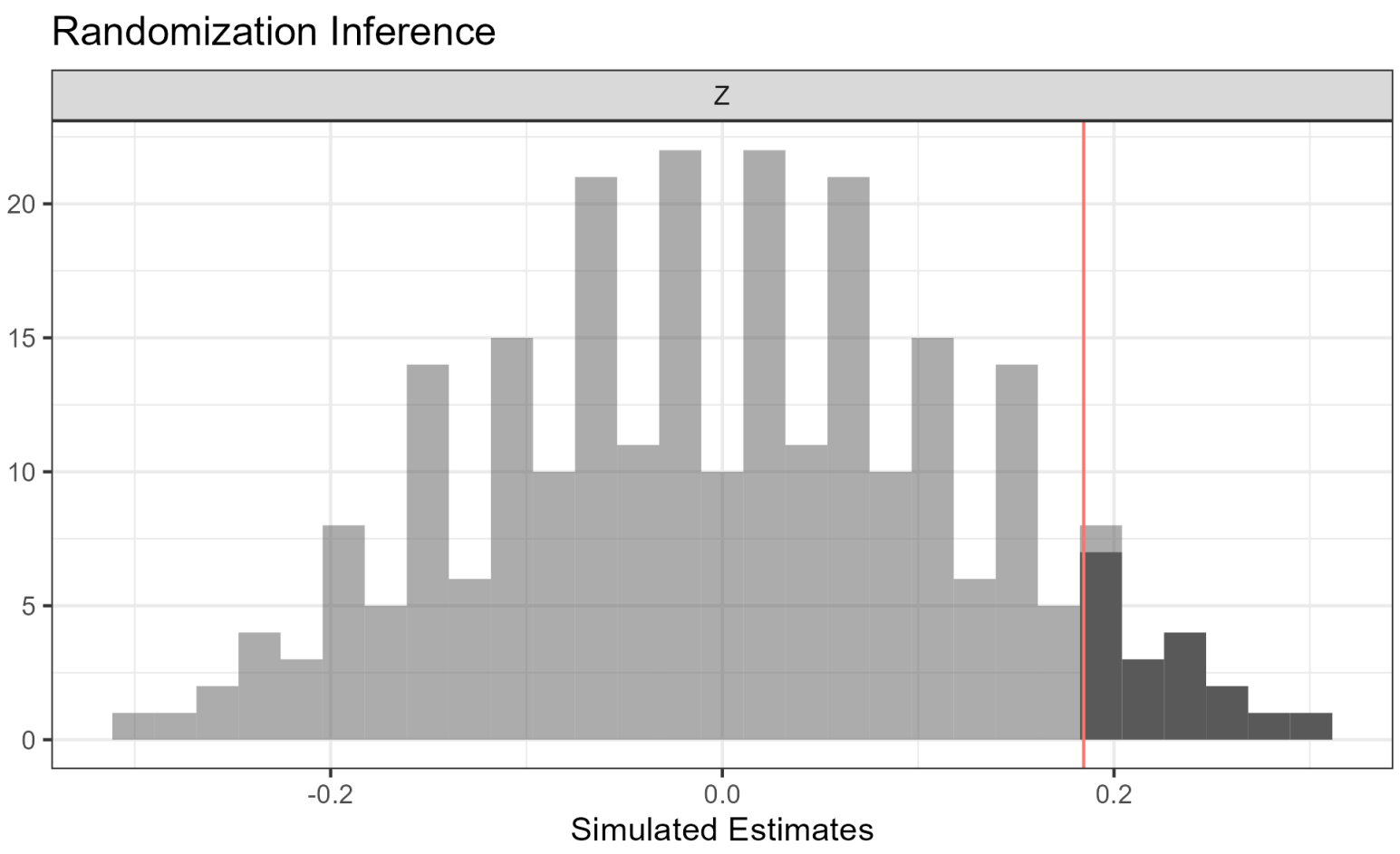

\begin{tabular}{l|l} 
Estimate & Observed Value
\end{tabular}

Figure A7: Effects on pluralism

\subsection{Behavioral scale}

The main text shows results on a composite index of three behavioral indicators. In a follow-up email that we sent to participants right after the town hall meeting, we offered multiple options to "take further action". To assess whether respondents in the democratic persuasion condition were more likely to get engaged for democracy we offered three behavioral options: Sign a petition on the defense of liberal democracy, sign a petition to hold elections despite the pandemic and to register for a newsletter on democracy. Table A5 shows the 3 actions broken down separately. No statistically significant differences emerge between the standard and the democratic persuasion town halls.

Table A5: Behavioral Outcomes

\begin{tabular}{l|r|r|r|r|r}
\hline Outcome & ITT & P-value & Cov-adj ITT & P-value & N \\
\hline Behavioural Scale & -0.055 & 0.703 & -0.056 & 0.684 & 213 \\
\hline Liberal Democracy Petition & 0.036 & 0.152 & 0.026 & 0.219 & 213 \\
\hline Election Petition & 0.002 & 0.477 & -0.006 & 0.562 & 213 \\
\hline Newsletter & -0.093 & 0.902 & -0.076 & 0.836 & 213 \\
\hline
\end{tabular}




\subsection{Ethical considerations}

The study was reviewed and approved by the Research Ethics Committee at (Anonymized University) under Ref: 11146.

All participants in the town hall meetings were fully aware and gave their consent that they participated in an academic study. On the first page of the survey that was used for registering town hall participants, participants were informed about the research project and gave their consent to participate in the study, have their data processed and recorded and to a video recording of the town hall meetings. Moreover, at the beginning of each town hall meeting, we reminded participants of these conditions. Hence, we tried to be as clear as possible that these town hall meetings were embedded in an academic study.

Participants were not fully aware of one aspects of the research project. In particular, participants were not informed about how the two experimental conditions that they were assigned to differed from each other. We decided to withhold this information for two reasons. First, we wanted to conduct the experiment in as natural an environment as possible, where the focus of the discussion was on the substantive topic. Second, we were worried that participants would change their responses on the outcome survey if they were told that we were studying how they respond to democratic persuasion. However, at all times, we kept the level of deception employed to an absolute minimum.

One may object that holding back this information limited participants' autonomy to choose a town hall meeting based on all available information as participants took part in a town hall meetings that would have been conducted somewhat differently if they had chosen a town hall meeting in the other experimental condition. It is important to stress that participants were not deceived with false pre-tense into participating in a town hall meeting that did not occur as advertised. Respondents were invited to town hall meetings to discuss Covid-19 politics with a member of parliament and participants in both experimental conditions participated in a town hall meeting with members of parliament on Covid-19 politics with the only difference that politicians in the democratic persuasion town halls talked more about the democracy-related aspects of the Covid-19 pandemic compared to the standard town halls.

Another potential ethical concern could be that participants were exposed to persuasive influences, which speaks to the impact principle highlighted in the APSA ethics guidelines. While it is true that our project was designed to ultimately affect citizens' attitudes, we believe to have employed persuasion for a just cause (fostering commitment to liberal democracy) and the treatment was implemented by legitimate political actors, elected democratic representatives. By selecting 4 legislators who belonged to government parties and 4 legislators who belonged to opposition parties, we tried to ensure that no democratic party gained a partisan advantage. Most importantly, by participating in a town hall meeting with a politician to discuss political issues, citizens were likely aware and prepared that they politicians will attempt to persuade them. The small scale of the town halls, that were designed to meet the requirements of statistical power, while minimizing aggregate political impact, as well as Germany's proportional electoral system, ensured that no aggregate political outcomes could reasonably have been affected by the study.

The treatment was designed to minimize the potential for negative individual experiences during the town hall. To assess whether the experiment could have negatively affected individual experiences, we fielded a questionnaire after the town hall to assess 
how participants rated the town halls. The results show that $63 \%$ of the participants liked the town hall a lot, $33 \%$ liked them somewhat and only $4 \%$ did not like the town hall meetings. Moreover, the qualitative feedback we received during the town halls and via email was extraordinarily positive and emphasized that participants were grateful for the chance to get in touch with legislators. 


\subsection{Comparison to general population}

This appendix compares the audience of the town hall meetings with the general population in Germany. Our goal in recruiting the sample was not a random draw from the general population. This goal is not feasible for several reasons including self-selection biases. Because participation comes with a substantial investment of time, we expected that, compared to the general population, citizens with higher levels of formal education or political interest would be overrepresented among the town hall participants. In that regard, we did not expect our sample to represent the general population. Yet, it is important to keep in mind that these biases represent natural selection processes. In other words, town halls meetings that were not organized by academics but by practitioners or the politicians themselves would likely be subject to similar selection processes.

Our goal in sample recruiting was to attract a mix of participants that would not be strongly skewed in any ideological direction. Even more important to our project is the distribution of democracy-related attitudes. Due to their lower levels of external political efficacy and lower levels of trust in political and academic elites, citizens with doubts about the democratic process might be more reluctant to join the town halls compared to highly satisfied and trusting citizens. To avoid preaching to the converted, our goal was to minimize this kind of bias and to attract a sizable number of wavering democrats.

Table A6 compares the distribution of attitudes and sociodemographic characteristics in the recruited sample with the general population. As data source for comparison with the general population we use ALLBUS 2018 ("German General Social Survey - ALLBUS 2018" 2019) which is one of the highest quality survey data on political attitudes of German citizens. ALLBUS is a bi-annual survey with respondents that were drawn in a two stage disproportionate random sample. In the first sample stage, municipalities were selected with a probability proportional to their number of adult residents; in the second sample stage, individual persons were selected at random from the municipal registers of residents. The sample universe includes all persons who resided in private households in Germany and were born before 1 January 2000.

Note that among town hall participants we measured satisfaction with democracy on a 5-point scale whereas ALLBUS measured satisfaction with democracy on a 6-point scale (which we recoded to a scale from 1 to 5). We measured ideology on an 11-point scale whereas ALLBUS measured ideology on a 10-point scale (which we recoded to a scale from 1 to 11). We report both dataset without survey weights.

Table A6 shows that our sample closely resembles the general population on an indicator of support for democracy. The mean level of satisfaction with democracy among town hall participants (column 2) is on a similar but slightly lower level compared to the general population (column 1). In other words, we succeeded in attracting participants with reservations about the democratic process. Regarding ideological self-placement, the differences are slightly more pronounced as the town hall participants are more left-wing compared to the general population.

Regarding sociodemographic variables, Table A6 shows substantial differences between the two samples along the expected lines. Men are overrepresented among town hall participants. Moreover, citizens with high levels of educations are overrepresented in the sample of participants compared to the general population. Finally, compared to the general population, fewer citizens attended the town halls who were very young or very old. 
Table A6: Comparison of town hall participants with general population

\begin{tabular}{lccc}
\hline Characteristic & $1, \mathrm{~N}=3,477$ & $2, \mathrm{~N}=183$ & $\mathrm{p}^{- \text {value }^{1}}$ \\
\hline Satisfaction with democracy & & & $<0.001$ \\
Mean, (Min-Max) & $3.63,(1.00-5.00)$ & $3.12,(1.00-5.00)$ & \\
Ideology (Left-right) & & & $<0.001$ \\
Mean, (Min-Max) & $5.43,(1.10-11.00)$ & $4.29,(1.00-9.00)$ & \\
Higher education, n (\%) & $1,075(31 \%)$ & $111(80 \%)$ & $<0.001$ \\
Female, n (\%) & $1,704(49 \%)$ & $53(38 \%)$ & 0.012 \\
Age, n (\%) & & & $<0.001$ \\
1 & $475(14 \%)$ & $10(7.2 \%)$ & \\
2 & $511(15 \%)$ & $36(26 \%)$ & \\
3 & $532(15 \%)$ & $22(16 \%)$ & \\
4 & $727(21 \%)$ & $32(23 \%)$ & \\
5 & $641(18 \%)$ & $29(21 \%)$ & \\
6 & $586(17 \%)$ & $10(7.2 \%)$ & \\
\hline
\end{tabular}

${ }^{1}$ Wilcoxon rank sum test; Pearson's Chi-squared test 


\subsection{Balance and randomization}

Table A7 compares the distribution of relevant socio-demographic characteristics and outcomes variables in the control and treatment groups.

Table A7: Descriptive statistics

\begin{tabular}{lccc}
\hline Characteristic & Control, N $=104$ & Treatment, N $=79$ & p-value $^{1}$ \\
\hline Female, n (\%) & $34(42 \%)$ & $19(32 \%)$ & 0.22 \\
Higher education, n (\%) & $60(75 \%)$ & $51(86 \%)$ & 0.10 \\
Satisfaction with democracy & $3.05,(1.00-5.00)$ & $3.22,(1.00-5.00)$ & 0.35 \\
Mean, (Min-Max) & & & 0.15 \\
Pluralism & $3.38,(1.00-4.00)$ & $3.63,(2.00-4.00)$ & \\
Mean, (Min-Max) & & & 0.66 \\
Democracy: Best Form of Gov & $4.60,(1.00-5.00)$ & $4.66,(2.00-5.00)$ & \\
Mean, (Min-Max) & & & 0.83 \\
Ideology (Left-right) & $4.35,(1.00-9.00)$ & $4.20,(1.00-8.00)$ & \\
Mean, (Min-Max) & & & \\
Corona: Trust in Gov & $2.48,(1.00-5.00)$ & $2.75,(1.00-5.00)$ & \\
Mean, (Min-Max) &
\end{tabular}

${ }^{1}$ Pearson's Chi-squared test; Wilcoxon rank sum test 
Table A8 below shows balance statistics for all covariates that are used in the analysis. For each regression, we include sex, age, education, ideology, East/West dummy, PID and a pre-treatment measure of the respective outcome.

Table A8: Balance table

\begin{tabular}{|c|c|c|c|}
\hline Characteristic & Control, $\mathrm{N}=104$ & Treatment, $\mathrm{N}=79$ & p-value ${ }^{1}$ \\
\hline Age, n (\%) & & & 0.022 \\
\hline 1 & $6(7.5 \%)$ & $4(6.8 \%)$ & \\
\hline 2 & $28(35 \%)$ & $8(14 \%)$ & \\
\hline 3 & $14(18 \%)$ & $8(14 \%)$ & \\
\hline 4 & $11(14 \%)$ & $21(36 \%)$ & \\
\hline 5 & $16(20 \%)$ & $13(22 \%)$ & \\
\hline 6 & $5(6.2 \%)$ & $5(8.5 \%)$ & \\
\hline Education, n (\%) & $60(75 \%)$ & $51(86 \%)$ & 0.087 \\
\hline Ideology (Left-right) & & & 0.64 \\
\hline Mean, (Min-Max) & $4.35,(1.00-9.00)$ & $4.20,(1.00-8.00)$ & \\
\hline East Germany, n (\%) & $7(6.7 \%)$ & $13(16 \%)$ & 0.048 \\
\hline Party ID, n (\%) & & & 0.10 \\
\hline 1 & $10(12 \%)$ & $5(8.5 \%)$ & \\
\hline 2 & $7(8.8 \%)$ & $11(19 \%)$ & \\
\hline 3 & $1(1.2 \%)$ & $1(1.7 \%)$ & \\
\hline 4 & $8(10 \%)$ & $5(8.5 \%)$ & \\
\hline 5 & $8(10 \%)$ & $7(12 \%)$ & \\
\hline 6 & $15(19 \%)$ & $18(31 \%)$ & \\
\hline 7 & $7(8.8 \%)$ & $5(8.5 \%)$ & \\
\hline 9 & $24(30 \%)$ & $7(12 \%)$ & \\
\hline Satisfaction with democracy & & & 0.36 \\
\hline Mean, (Min-Max) & $3.05,(1.00-5.00)$ & $3.22,(1.00-5.00)$ & \\
\hline Concern Dem. Rights & & & 0.41 \\
\hline Mean, (Min-Max) & $2.80,(1.00-5.00)$ & $3.02,(1.00-5.00)$ & \\
\hline Pluralism & & & 0.044 \\
\hline Mean, (Min-Max) & $3.38,(1.00-4.00)$ & $3.63,(2.00-4.00)$ & \\
\hline
\end{tabular}




\begin{tabular}{|c|c|c|c|}
\hline Characteristic & Control, $\mathrm{N}=104$ & Treatment, $\mathrm{N}=79$ & p-value ${ }^{1}$ \\
\hline Democracy: Best Form of Gov & & & 0.61 \\
\hline Mean, (Min-Max) & $4.60,(1.00-5.00)$ & $4.66,(2.00-5.00)$ & \\
\hline Populism & & & 0.040 \\
\hline Mean, (Min-Max) & $9.38,(3.00-15.00)$ & $8.54,(3.00-15.00)$ & \\
\hline Attitudes Covid & & & 0.24 \\
\hline Mean, (Min-Max) & $1.15,(0.00-3.00)$ & $1.39,(0.00-3.00)$ & \\
\hline Corona: Trust in Gov) & & & 0.20 \\
\hline Mean, (Min-Max) & $2.48,(1.00-5.00)$ & $2.75,(1.00-5.00)$ & \\
\hline blocks, n (\%) & & & 0.13 \\
\hline 1 & $5(4.8 \%)$ & $8(10 \%)$ & \\
\hline 2 & $19(18 \%)$ & $16(20 \%)$ & \\
\hline 3 & $14(13 \%)$ & $8(10 \%)$ & \\
\hline 4 & $8(7.7 \%)$ & $10(13 \%)$ & \\
\hline 5 & $15(14 \%)$ & $10(13 \%)$ & \\
\hline 6 & $14(13 \%)$ & $14(18 \%)$ & \\
\hline 7 & $16(15 \%)$ & $7(8.9 \%)$ & \\
\hline 8 & $13(12 \%)$ & $6(7.6 \%)$ & \\
\hline
\end{tabular}

${ }^{1}$ Welch Two Sample t-test 


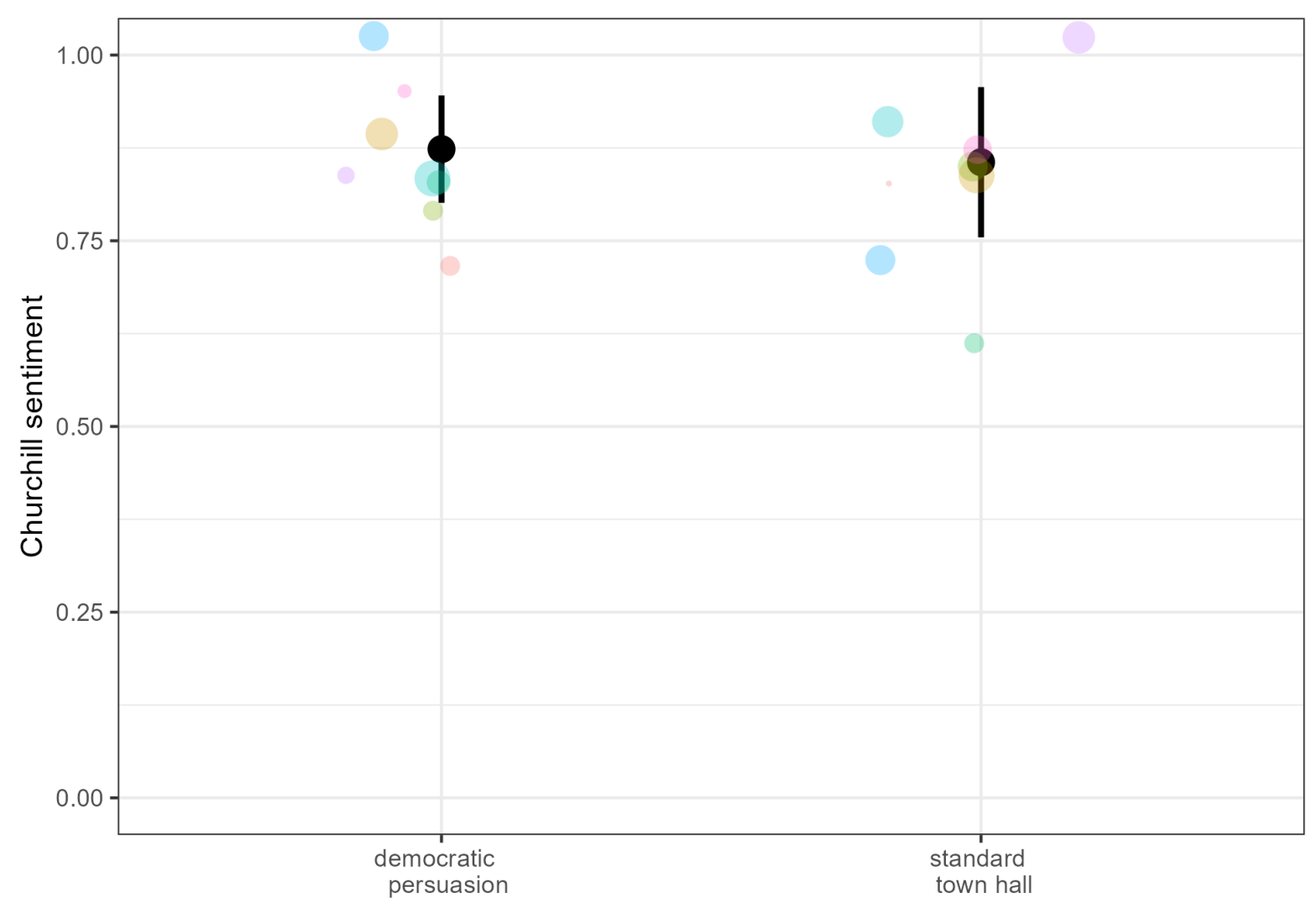

Figure A8: Despite faults, democracy is best form of government

\subsection{Secondary outcomes}

Table A9 displays effects of democratic persuasion on the pre-registered secondary outcomes. One reason why we declared these variables as secondary in the pre-analysis plan was that we anticipated difficulties to find significant effects due to floor and ceiling effects as both variables are severely skewed (see table on distributions in main text).

Effects on both variables go in the expected directions. Compared to the standard town hall, respondents in the democratic persuasion town halls expressed stronger support for democracy ("Churchill sentiment") and they were less likely to express populist attitudes. Yet, none of the differences between the experimental groups are statistically significant.

Table A9: Secondary Outcomes

\begin{tabular}{l|r|r|r|r|r}
\hline Outcome & ITT & P-value & Cov-adj ITT & P-value & N \\
\hline Churchill sentiment & 0.018 & 0.355 & 0.033 & 0.273 & 181 \\
\hline Populism & -0.106 & 0.199 & 0.026 & 0.602 & 181 \\
\hline
\end{tabular}

The following plots display the averages in treatment and control town halls for our secondary outcomes. 


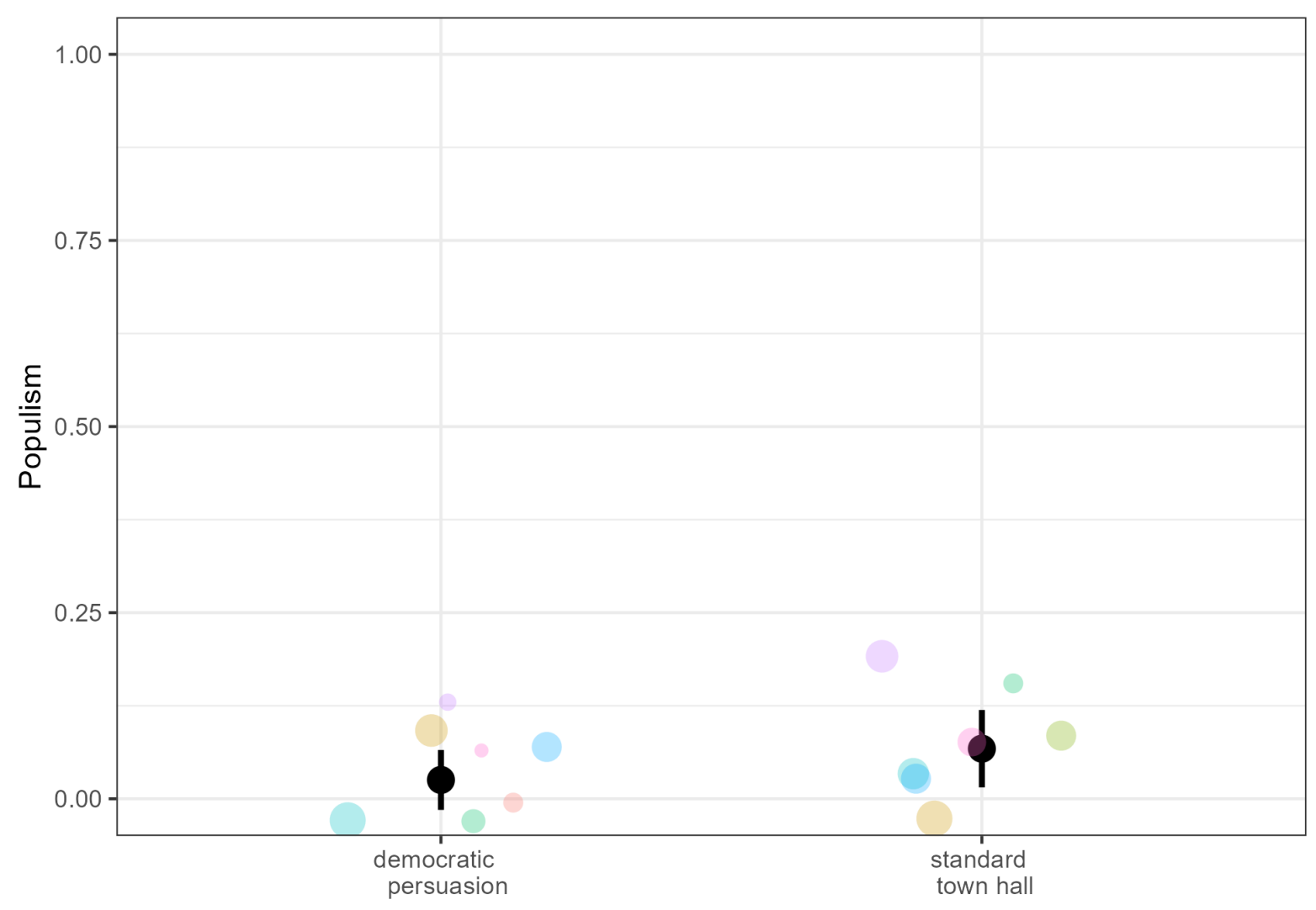

Figure A9: Populist attitudes

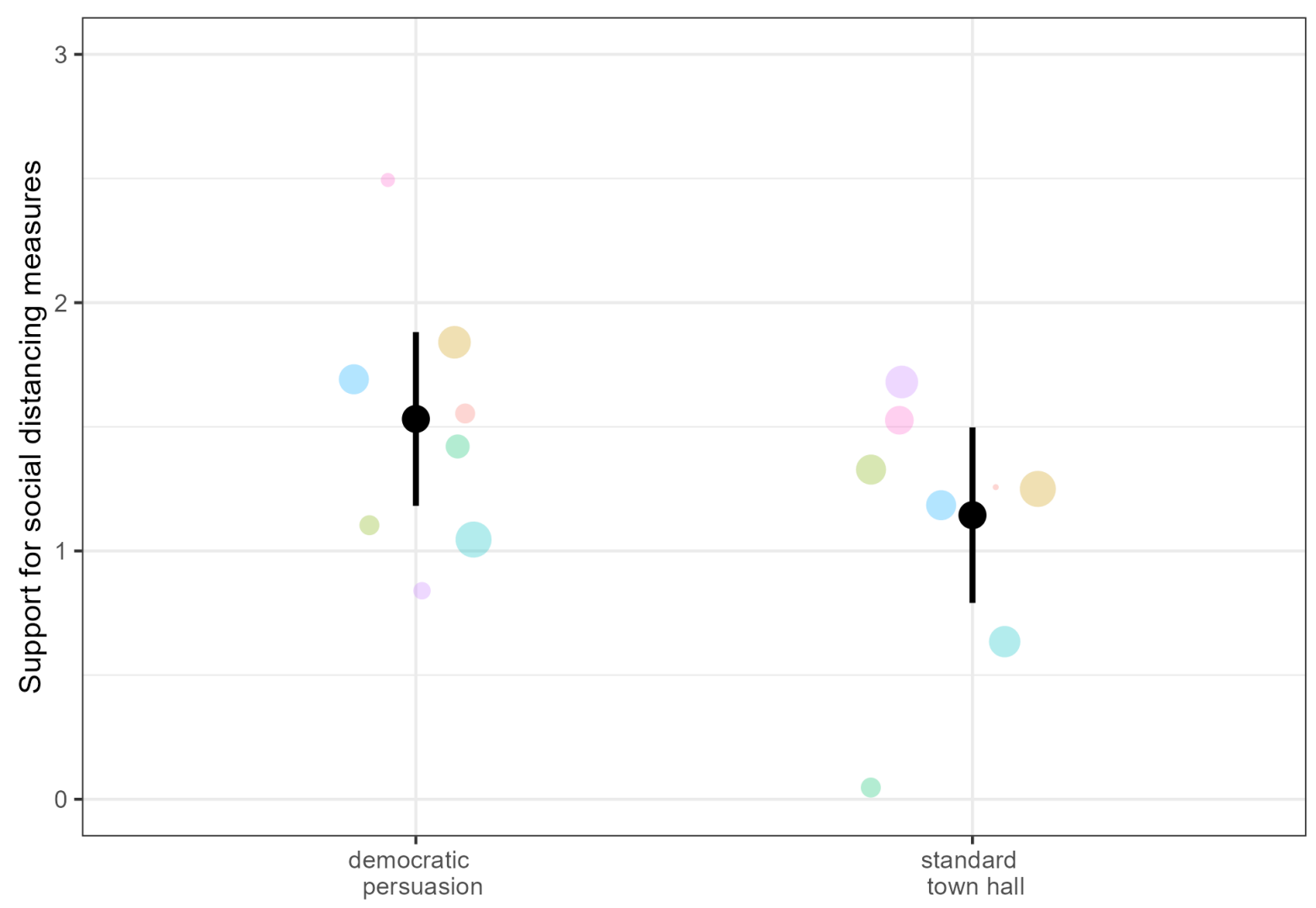

Figure A10: Support for measures of social distancing 


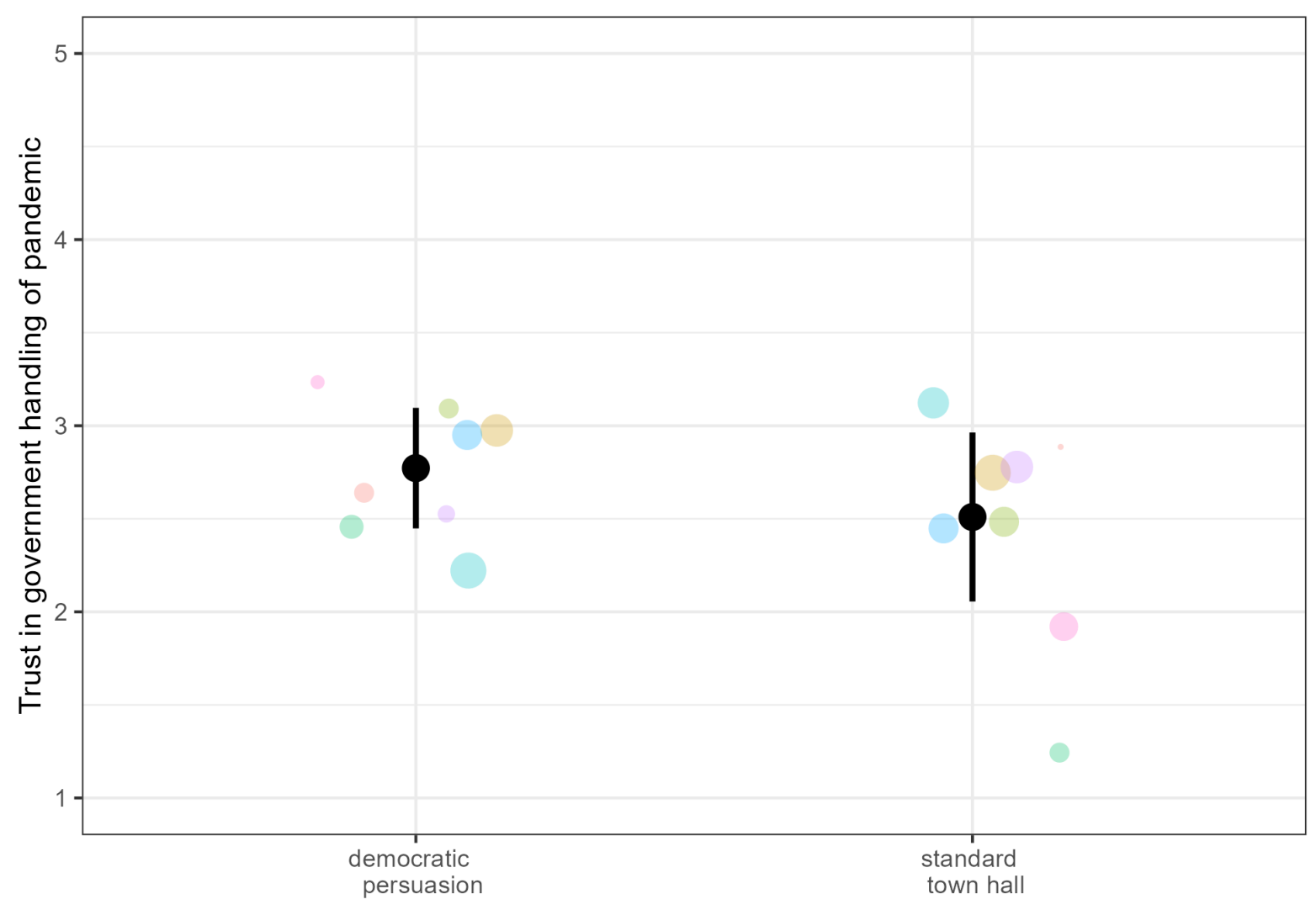

Figure A11: Trust in government handling of Corona pandemic

Table A10: COVID-related Outcomes

\begin{tabular}{l|r|r|r|r|r}
\hline Outcome & ITT & P-value & Cov-adj ITT & P-value & N \\
\hline Support COVID Measures & 0.387 & 0.051 & 0.268 & 0.078 & 181 \\
\hline Trust in Government & 0.263 & 0.172 & 0.152 & 0.324 & 181 \\
\hline
\end{tabular}

Table A11: Manipulation Check

\begin{tabular}{l|r|r|r|r|r}
\hline Outcome & ITT & P-value & Cov-adj ITT & P-value & N \\
\hline COVID airborne & -0.038 & 0.898 & -0.039 & 0.930 & 181 \\
\hline Germany model in pandemic & -0.052 & 0.855 & -0.025 & 0.715 & 181 \\
\hline
\end{tabular}




\subsection{Effects of participating in any town hall}

For many of the participants, the town hall meeting was the first time they could publicly discuss views on Covid-19 politics, which many experienced as pressing, personal and polarizing issue. Hence, it is conceivable that, irrespective of treatment assignment, participation in the town hall meetings alone might have had effects on citizen attitudes. However, as discussed in Appendix 9.4 our project was not designed to identify these effects.

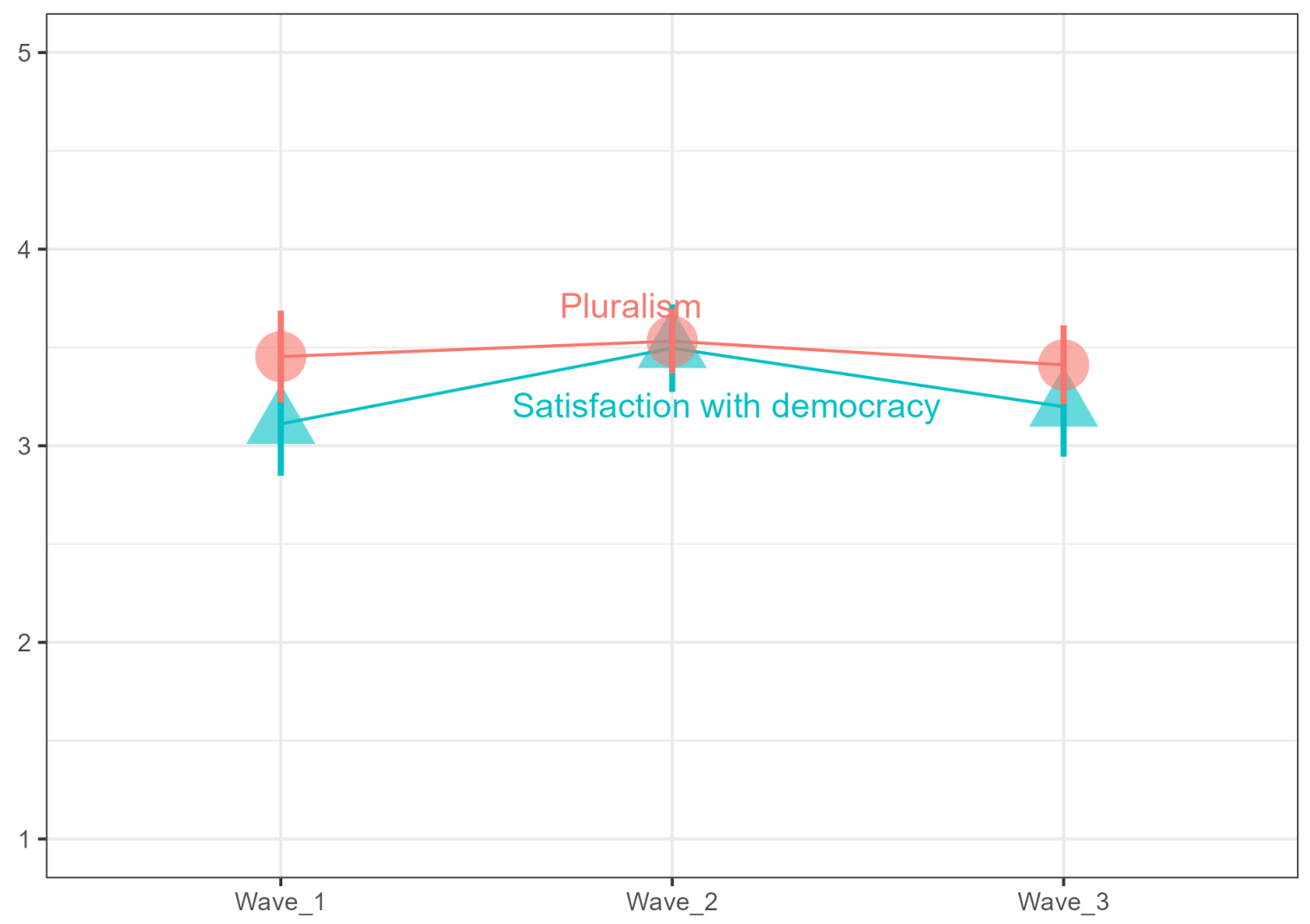

Figure A12: Town hall effect

In this appendix, we report attitudinal dynamics between the survey waves. Yet, it is important to keep in mind that town hall participation is only one factor of several that drive these dynamics. Other factors also play a role in shaping attitudes between survey waves as the town hall meetings took part amid the second wave of the Covid-19 pandemic in Germany (see Appendix 9.4). Therefore, readers should be hesitant to give the the estimates reported in this appendix a causal interpretation.

Figure A12 shows trends in democracy-related attitudes among respondents who responded to all three panel waves: a few weeks before the town hall meeting, immediately after the town hall, and about four weeks after the town hall. Support for pluralist values remained fairly stable across all three survey waves. Satisfaction with democracy exhibits more fluctuation. Average levels increased after the town hall meetings and reverted to initial levels a few weeks later. 


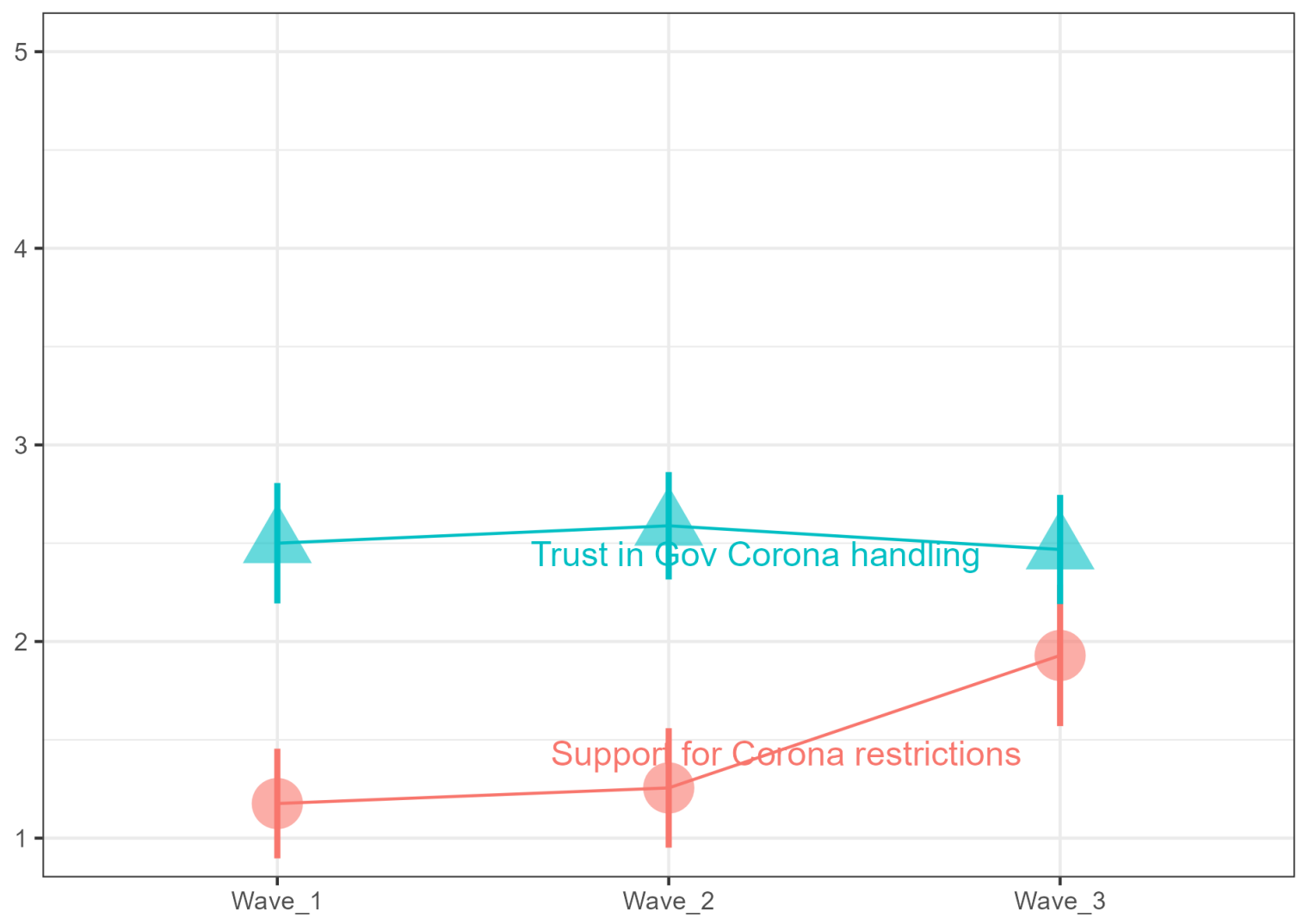

Figure A13: Town hall effect

Figure A13 shows the development of attitudes towards an index of support for several Covid-19 restrictions and trust in the government's Covid-19 response. Trust in the government's Covid-19 response is fairly stable across waves, whereas support for Covid-19 restrictions increased between survey waves 2 and 3, presumably reflecting the increasing number of infections during that time period. 


\subsection{Anonymized pre-analysis plan}

Journal formatting and appendix length requirements do not permit including a copy of the pre-analysis plan in this appendix but a copy can be requested from the editorial office.

\subsection{Effect heterogeneity}

In this appendix, we examine whether persuasive effects depend on the alignment between the respondent's and the politician's party affiliation and whether the politician belongs to a federal opposition party. For the first analysis, we used pre-treatment information on the respondent's self-reported party identification to generate a binary variable which indicates whether the respondent's and the politician's party affiliation align or not. For the second analysis, we test if the effect of the treatment is stronger when delivered by a politician who belongs to one of the federal opposition parties. Effect heterogeneity conditional on party alignment and opposition/government party affiliation could provide us with tentative evidence on the mechanisms through which persuasive effects materialize. If respondents are more susceptible to persuasive influence from like-minded politicians this could indicate the role of source cues (instead of message characteristics). If respondents are more susceptible to persuasive influence from opposition politicians, this could indicate that the intervention needs opposition buy-in to succeed.

The results shows no moderating effect of partisan alignment on how strongly the treatment affects satisfaction with democracy, endorsement of pluralism or concerns about democratic rights. Hence, there is no evidence of sources cues at play. 
Table A12: Moderating effect of partisan alignment

\begin{tabular}{lccc}
\hline & Satisfaction & Pluralism & Concerns \\
\hline Intercept $)$ & $3.49^{* *}$ & $3.40^{* * *}$ & $0.48+$ \\
& $(0.40)$ & $(0.19)$ & $(0.17)$ \\
alignment & 0.34 & 0.10 & 0.10 \\
& $(0.27)$ & $(0.19)$ & $(0.12)$ \\
treatment & 0.29 & 0.14 & -0.12 \\
& $(0.18)$ & $(0.09)$ & $(0.11)$ \\
alignment $\times$ treatment & 0.23 & 0.12 & 0.01 \\
& $(0.33)$ & $(0.20)$ & $(0.20)$ \\
\hline Num.Obs. & 183 & 183 & 183 \\
R2 & 0.209 & 0.212 & 0.124 \\
R2 Adj. & 0.127 & 0.131 & 0.034 \\
Std.Errors & by: clusters by: clusters by: clusters \\
\hline+ p $<0.1, *$ p $<0.05, * *$ p $<0.01, * * * p<0.001$
\end{tabular}


Table A13: Moderating effect of opposition party

\begin{tabular}{lccc}
\hline & Satisfaction & Pluralism & Concerns \\
\hline Intercept $)$ & $3.32^{*}$ & $3.30^{* *}$ & $0.48+$ \\
& {$[2.31,4.33]$} & {$[2.54,4.05]$} & {$[-0.29,1.25]$} \\
opposition & -0.68 & -0.29 & 0.26 \\
& {$[-2.63,1.26]$} & {$[-0.94,0.36]$} & {$[-0.82,1.33]$} \\
treatment & 0.36 & 0.15 & -0.03 \\
& {$[-0.20,0.91]$} & {$[-0.24,0.53]$} & {$[-0.20,0.14]$} \\
opposition $\times$ treatment & 0.10 & 0.14 & -0.29 \\
& {$[-0.79,0.98]$} & {$[-0.32,0.61]$} & {$[-0.84,0.25]$} \\
\hline Num.Obs. & 183 & 183 & 183 \\
R2 & 0.105 & 0.108 & 0.085 \\
R2 Adj. & 0.059 & 0.062 & 0.037 \\
Std.Errors & by: clusters & by: clusters & by: clusters \\
\hline$+\mathrm{p}<0.1, * \mathrm{p}<0.05, * * \mathrm{p}<0.01, * * *$ & $\mathrm{p}<0.001$ &
\end{tabular}

